\title{
In Situ TEM of Radiation Effects in Complex Ceramics
}

\author{
JIE LIAN, ${ }^{1,2} *$ L.M. WANG ${ }^{3,4}$ KAI SUN, ${ }^{4}$ AND RODNEY C. EWING ${ }^{2,3,4 *}$ \\ ${ }^{1}$ Department of Mechanical, Aerospace and Nuclear Engineering, Rensselaer Polytechnic Institute, Troy, New York 12180 \\ ${ }^{2}$ Department of Geological Sciences, University of Michigan, Ann Arbor, Michigan 48109-1005 \\ ${ }^{3}$ Department of Nuclear Engineering and Radiological Sciences, University of Michigan, Ann Arbor, Michigan $48109-1005$ \\ ${ }^{4}$ Department of Materials Science and Engineering, University of Michigan, Ann Arbor, Michigan 48109-1005
}

\begin{abstract}
KEY WORDS $\quad$ radiation effects; in-situ TEM; complex ceramics; amorphization; order-disorder phase transformation
\end{abstract}

\begin{abstract}
In situ transmission electron microscopy (TEM) has been extensively applied to study radiation effects in a wide variety of materials, such as metals, ceramics and semiconductors and is an indispensable tool in obtaining a fundamental understanding of energetic beam-matter interactions, damage events, and materials' behavior under intense radiation environments. In this article, in situ TEM observations of radiation effects in complex ceramics (e.g., oxides, silicates, and phosphates) subjected to energetic ion and electron irradiations have been summarized with a focus on irradiation-induced microstructural evolution, changes in microchemistry, and the formation of nanostructures. New results for in situ TEM observation of radiation effects in pyrochlore, $\mathrm{A}_{2} \mathrm{~B}_{2} \mathrm{O}_{7}$, and zircon, $\mathrm{ZrSiO}_{4}$, subjected to multiple beam irradiations are presented, and the effects of simultaneous irradiations of $\alpha$-decay and $\beta$-decay on the microstructural evolution of potential nuclear waste forms are discussed. Furthermore, in situ TEM results of radiation effects in a sodium borosilicate glass subjected to electron-beam exposure are introduced to highlight the important applications of advanced analytical TEM techniques, including Z-contrast imaging, energy filtered TEM (EFTEM), and electron energy loss spectroscopy (EELS), in studying radiation effects in materials microstructural evolution and microchemical changes. By combining ex situ TEM and advanced analytical TEM techniques with in situ TEM observations under energetic beam irradiations, one can obtain invaluable information on the phase stability and response behaviors of materials under a wide range of irradiation conditions. Microsc. Res. Tech. 72:165-181, 2009. @ 2009 Wiley-Liss, Inc.
\end{abstract}

\section{INTRODUCTION}

Energetic beam irradiations, including ion beam and electron beam, have been widely used to simulate the microstructural evolution and structural transformation in complex ceramics caused by $\alpha$-decay, $\beta$-decay, neutron, and fission fragment damage under carefully controlled experimental conditions (e.g., ion mass and energy, temperature, and fluence). Significant irradiation damage levels can be reached in short periods of time (e.g., minutes). Heavy ion beam irradiations can be used to simulate the recoil damage from the $\alpha$-decay events of the incorporated actinides in materials. The radiation damage from $\alpha$-particles can be simulated by light ion irradiations (e.g., $\mathrm{H}^{+}$or $\mathrm{He}^{2+}$ ). Electron irradiation damage can be used for simulating the effects of ionization and electronic excitations from $\beta$-particles.

TEM is a powerful tool for the analysis of defects in solids induced by ion and electron irradiations. Conventional TEM techniques, such as bright-field and dark-field imaging, diffraction, high resolution electron microscopy, and chemical analysis, such as energy dispersive X-ray spectroscopy (EDS), have been widely utilized to characterize irradiation-induced defects (e.g., dislocation loops, voids, and bubbles), structural changes (e.g., crystalline-to-amorphous transition and order-disorder phase transitions), and chemical variations. Specifically, the microstructure evolution of materials under energetic beam irradiations can be imaged by TEM with high spatial resolution (less than
$0.2 \mathrm{~nm}$ ), and both crystal structure and local chemistry variation can be probed by electron diffraction and EDS or EELS, respectively.

In situ TEM is particularly useful for studying radiation effects of materials as it allows one to follow the microstructural evolution under well-controlled conditions of irradiation dose and temperature, which provides critical information for understanding the defect production and annihilation processes during the damage process. In situ TEM observation of radiation effects originated from the utilization of high voltage electron microscopy in which simple Frenkel pairs were produced by energetic electron beam irradiation. Earlier experiments of in situ TEM observation and ion irradiation were mainly focused on the radiationinduced dislocation loops, void/bubble formation, and precipitation in metals used as nuclear reactor components. Since then, extensive experiments have been completed using in situ TEM observation and heavy ion irradiations to study radiation-induced microstructural evolution in a wide variety of materials, such as

\footnotetext{
*Correspondence to: Jie Lian and Rodney C. Ewing, Department of Geological Sciences, University of Michigan, Ann Arbor, Michigan 48109-1005, USA E-mail: lianj@rpi.edu and rodewing@umich.edu

Received 18 February 2008; accepted in revised form 28 August 2008

Contract grant sponsor: Office of Basic Energy Sciences (U.S. Department of Energy); Contract grant number: DE-FG02-97ER45656.

DOI 10.1002/jemt.20669

Published online 7 January 2009 in Wiley InterScience (www.interscience. wiley.com).
} 

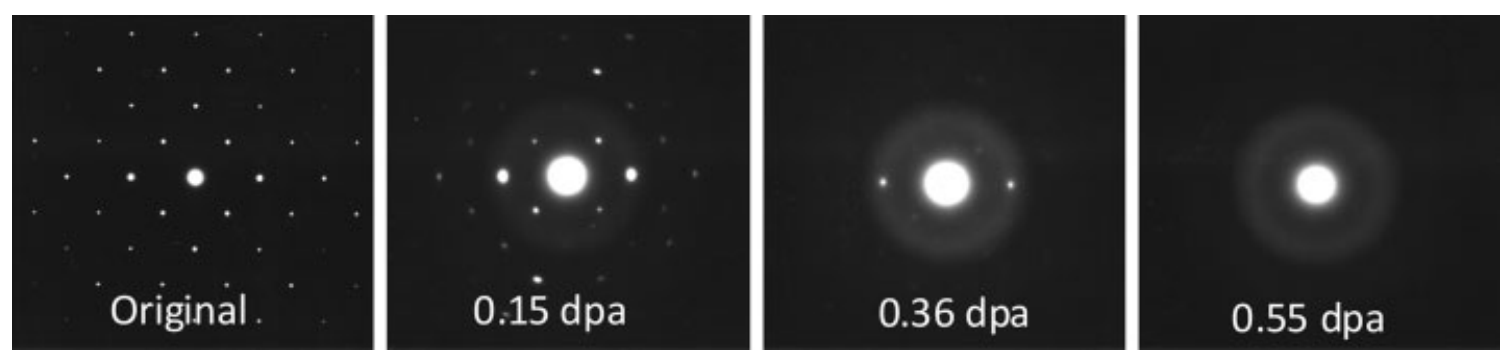

Fig. 1. Sequence of in situ selected area electron diffraction patterns of zircon irradiated by $1.5 \mathrm{MeV}$ $\mathrm{Kr}^{+}$at room temperature as a function of dose (Modified with permission from Wang and Ewing, Mater Res Soc Bull, 1992b, 17, 38-44, Material Research Society).

intermetallics, semiconductors, ceramics, and nuclear waste forms. In situ TEM studies of cascade damage in materials as well as individual damage events by single ion has been well-established, taking the advantages of in situ observation, such as maintaining sample position and orientation at well-controlled temperatures. Materials modifications and nanoscale engineering by ion implantation were also performed combined with in situ TEM observation. The historical development of in situ TEM facilities and their applications in studying radiation effects have been previously summarized in excellent review articles (Allen, 1994; Birtcher et al., 2005; Ishino, 1997; Wang, 1998).

In this article, in situ TEM studies of radiation effects in complex ceramics (e.g., zircon, pyrochlore, apatite, and perovskite) upon energetic ion and electron beam irradiations are briefly reviewed with a focus on radiation-induced microstructural evolution including amorphization, order-disorder transitions, phase decomposition, recrystallization and defect annealing, and nanostructure formation. The original results of multiple beam irradiations combining with in situ TEM observation on pyrochlore and zircon are presented and compared with the single beam irradiation results to highlight the importance of studying simultaneous ballistic and electronic ionization effects. The application of advanced analytical TEM techniques (e.g., EELS, EFTEM, and Z-contrast imaging) for the in situ TEM observation of radiation effects is demonstrated, and examples of radiation effects in a sodium borosilicate glass irradiated by an energetic e-beam are illustrated. Most of the ion beam irradiation experiments were performed using the HVEM-Tandem (now dismantled) and IVEM-Tandem facilities at Argonne National Laboratory. Multiple beam irradiations of pyrochlore and zircon were performed at Hokkaido University. E-beam irradiations were performed at the TEM facilities (e.g., JEOL 2000 FX and JEOL 2010 F) at Electron Microbeam Analysis Laboratory (EMAL) at University of Michigan.

\section{IN SITU TEM OBSERVATION OF RADIATION-INDUCED AMORPHIZATION}

Radiation-induced amorphization occurs in natural minerals (metamictization) that contain radioactive elements. The alpha recoil damage in minerals and synthetic ceramics (e.g., those doped with highly active radionuclides, such as ${ }^{238} \mathrm{Pu}$ and ${ }^{244} \mathrm{Cm}$ ) can be simulated using heavy ion irradiation combined with in situ TEM observation (Wang and Ewing, 1992a; Weber et al., 1994). The microstructural evolution of materials upon ion irradiation can be followed by monitoring the electron diffraction patterns as a function of fluence and temperature. The critical amorphization fluence (dose) is the point at which all of the diffraction maxima have disappeared in the selected area electron diffraction pattern. Based on this type of data, collected over a range of temperatures, the critical amorphization temperature, $T_{\mathrm{c}}$, can be determined by fitting the experimental data to models that describe the temperature dependence of critical dose (Wang et al., 2001; Weber, 2000). Generally, the radiation response of a material is judged by the critical amorphization temperature (lower temperatures mean that it is harder to amorphize the material) or the critical amorphization dose at room temperature (lower doses mean that the material is easier to be amorphized).

\section{Zircon}

The first in situ TEM observation of radiation effects in ceramics by heavy ion irradiation was performed on complex silicate structures such as zircon and olivine (Eby et al., 1992; Wang et al., 1991), and a correlation of amorphization dose and chemical and structural complexity of materials was established. Wang et al. (1991) and Wang and Ewing (1992a) conducted additional, systematic ion beam irradiation studies of zircon using a variety of ion species and energies, e.g., including 700 and $1,500 \mathrm{keV} \mathrm{Kr}^{+}, 1,500 \mathrm{keV} \mathrm{Xe}^{+}$, and $400 \mathrm{keV} \mathrm{He}^{+}$; and the role of electronic or ionization process versus ballistic effects during damage accumulation was investigated. The complete crystalline-toamorphous structural transformation occurred at a dose of $\sim 0.55 \mathrm{dpa}$ upon $\mathrm{Kr}^{+}$and $\mathrm{Xe}^{+}$irradiation, regardless of total ionization energy deposited (Fig. 1). The microstructural evolution of materials upon heavy ion irradiation was further revealed by ex situ high resolution TEM imaging (Fig. 2). No indication of amorphization was observed in zircon upon $400 \mathrm{keV} \mathrm{He}{ }^{+}$irradiation, for which there is a high electronic/nuclear energy loss ratio. Weber et al. (1994) reported a comparable microstructural evolution of zircon upon heavy ion irradiation with natural zircon containing uranium and thorium and a $\mathrm{Pu}$-doped zircon, despite 

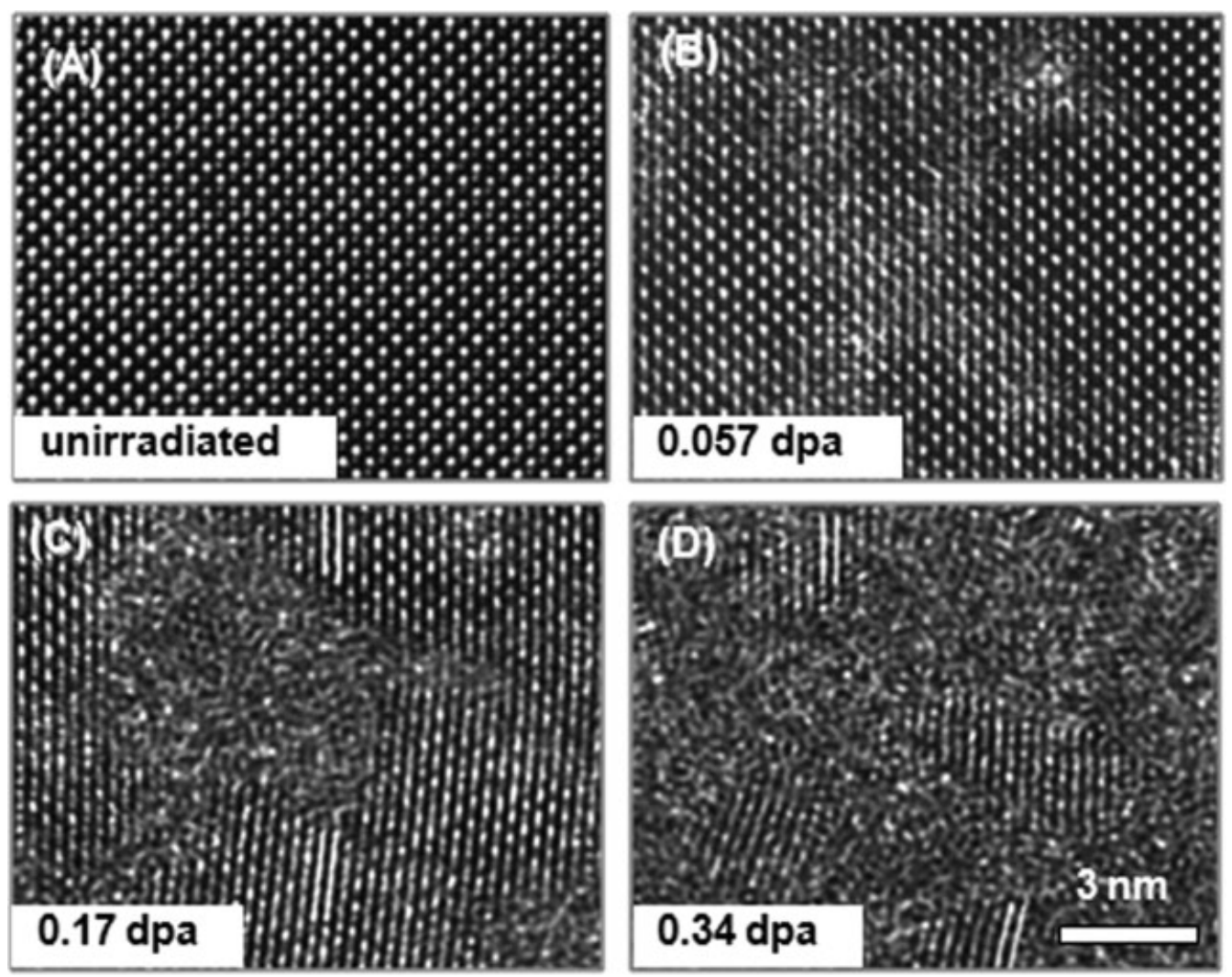

Fig. 2. Ex situ HRTEM images of crystalline to amorphous transformation in synthetic zircon irradiated with $1.5 \mathrm{MeV} \mathrm{Kr}^{+}$ions at $300 \mathrm{~K}:(\mathbf{A})$ unirradiated; (B) $0.057 \mathrm{dpa}$; (C) $0.17 \mathrm{dpa}$; and (D) $0.34 \mathrm{dpa}$. Complete amorphization was achieved at $0.55 \mathrm{dpa}$ (Modified with permission from Weber et al., J Mater Res, 1994, 9, 688-698, Material Research Society).

the fact that there were six order magnitudes difference in the damage rate. This classic study established the efficacy of using ion beam techniques to simulate $\alpha$ decay event damage in ceramics. Additional studies showed that the critical amorphization temperature for zircon irradiated with $1.0 \mathrm{MeV} \mathrm{Ne}^{+}, 800 \mathrm{keV} \mathrm{Kr}^{+}$, $800 \mathrm{keV} \mathrm{Xe}^{+}$, and $0.6 \mathrm{MeV} \mathrm{Bi}^{+}$was roughly constant, $\sim 1,000 \mathrm{~K}$, and at room temperature the amorphization dose was approximately the same for the Pu-doped sample and the ion beam irradiated zircon (Weber et al., 1999) (Fig. 3A). These results firmly established the value of using ion beam irradiation experiments combined with in situ TEM to investigate the effects of $\alpha$-decay events in ceramics.

Systematic in situ TEM observation and heavy ion irradiation experiments on a wide range of chemical compositions of zircon and monazite, e.g., $\mathrm{CaPO}_{4}$, showed that the critical amorphization temperature increases with the atomic mass of the target (Meldrum et al., 1999). Radiation damage in zircon results in the simultaneous accumulation of both point defects and amorphous regions. Displacement damage by nuclear collision is the controlling mechanism in radiationinduced amorphization of zircon (Wang and Ewing, 1992a). For zircon, in plots of amorphization dose versus temperature, damage accumulation appears to be a two-step process (Meldrum et al., 1999; Weber et al.,
1994) reflecting the recovery of isolated defects at low temperatures and cascade annealing at higher temperatures (Fig. 3A). The amorphization process is consistent with models based on the multiple overlap of particle tracks, suggesting that amorphization occurs as a result of a critical defect concentration (Weber, 2000; Weber et al., 1997). The in situ TEM results of radiation effects in zircon have been summarized in previous review articles (Ewing et al., 2000, 2003).

Following these early in situ TEM studies of radiation effects in zircon, extensive experiments were performed on a wide variety of ceramics, such as pyrochlore (Ewing et al., 2004; Lian et al., 2002b, 2003a, 2004a,b, 2006a,c, 2007a; Lumpkin, 2006; Lumpkin et al., 2004; Meldrum et al., 2001; Wang et al., 1999c, 2000c), perovskite (Sabathier et al., 2005; Smith and Zaluzec, 2005; Soulet et al., 2001b; Trachenko et al., 2004) and zirconolite (Berry et al., 2005; Ewing and Wang, 1992; Hadley et al., 2005; Lumpkin, 2001; Smith et al., 1997; Wang et al., 1999c, 2000b), apatites (Meldrum et al., 1997b; Utsunomiya et al., 2003; Wang and Ewing, 1992b; Wang et al., 1994), brannerite (Lian et al., 2002a; Lumpkin et al., 2001), spinel (Bordes et al., 1995; Yasuda et al., 1998), alumina (Pells, 1994), garnet (Utsunomiya et al., 2002, 2005), and murataite (Lian et al., 2005b,c), and the damage mechanisms and materials response have been investigated as a 

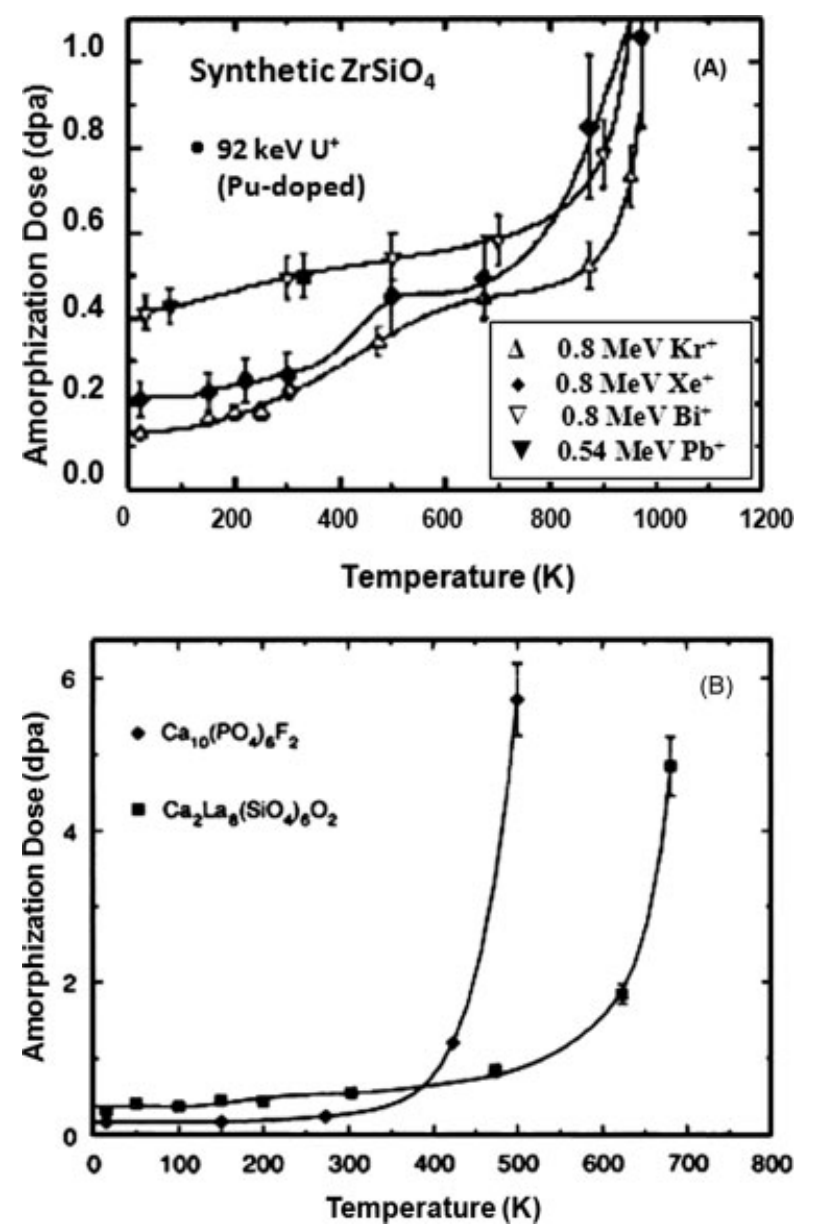

Fig. 3. A: Temperature dependence of amorphization dose in synthetic zircons under irradiation with different ions and including the results from alpha decay in Pu-doped zircon (Modified with permission from Weber et al., Material Research Society Symposium Proceedings, 1999, 367, Materials Research Society); B: Temperature dependence of critical amorphization doses (dpa) for $1.5 \mathrm{KeV} \mathrm{Kr}$ ion irradiated $\mathrm{Ca}_{10}\left(\mathrm{PO}_{4}\right)_{6} \mathrm{~F}_{2}$ and $\mathrm{Ca}_{2} \mathrm{La}_{8}\left(\mathrm{SiO}_{4}\right)_{6} \mathrm{O}_{2}$ (Wang et al., 1994).

function of chemical composition (Lian et al., 2006c; Meldrum et al., 2001), ionicity (Hobbs, 1994) and glass forming ability (Wang et al., 1998a,b), structural and topographical variations (Hobbs, 1995; Hobbs et al., 1996; Jesurum et al., 1998).

\section{Apatites}

The damage evolution of a fluorapatite, $\mathrm{Ca}_{10}\left(\mathrm{PO}_{4}\right)_{6} \mathrm{~F}_{2}$, and a silicate apatite, $\mathrm{Ca}_{2} \mathrm{La}_{8}\left(\mathrm{SiO}_{4}\right)_{6} \mathrm{O}_{2}$, irradiated by $1.5 \mathrm{MeV} \mathrm{Kr}^{+}$was investigated using the HVEM-Tandem Facility at Argonne National Laboratory (Wang et al., 1994), and the ion irradiation was performed over a wide temperature range (15-680 K) combined with in situ TEM observation. The highenergy $\mathrm{Kr}^{+}$ions can directly displace the target atoms through ballistic interactions and cause displacement cascades through a branching chain of collisions. As a result, solid-state amorphization occurred for both apatite compositions. The temperature dependence of the critical amorphization dose for the two apatite compositions are shown in Figure 3B. At low temperatures, $\mathrm{Ca}_{10}\left(\mathrm{PO}_{4}\right)_{6} \mathrm{~F}_{2}$ amorphized at lower doses than $\mathrm{Ca}_{2} \mathrm{La}_{8}$
$\left(\mathrm{SiO}_{4}\right)_{6} \mathrm{O}_{2}$. However, the critical amorphization dose increased much more rapidly for the phosphate phase above $350 \mathrm{~K}$ than the silicate composition due to a much lower activation energy for the recovery process in the phosphate structure. At $475 \mathrm{~K}$, the critical amorphization dose for the phosphate apatite was five times higher than that for the silicate. The critical amorphization temperature was $\sim 500 \mathrm{~K}$ for the phosphate versus $\sim 700 \mathrm{~K}$ for the silicate apatite. The lower critical amorphization dose at low temperatures and the lower activation energy for recovery of the phosphate apatite were attributed to the weaker P-O bond and the higher fluorine mobility in the phosphate (Wang et al., 1994). Soulet et al. (2001a) reported that the critical amorphous doses for fluorapatite and mono-silicate fluorapatite irradiated by $320 \mathrm{keV} \mathrm{Pb}^{+}$at room temperature were 0.65 and $0.45 \mathrm{dpa}$, respectively. Synthetic britholites were irradiated by $1.0 \mathrm{MeV} \mathrm{Kr}^{2+}$ and $1.5 \mathrm{MeV} \mathrm{Xe}^{+}$over the temperature range of 50 $973 \mathrm{~K}$ (Utsunomiya et al., 2003). The critical temperatures for amorphization were high, between 910 and $1,010 \mathrm{~K}$; however, electron irradiation experiments showed that ionizing radiation resulted in recrystallization at an absorbed dose of $6.2 \times 10^{13}$ Gy. Thus, for the phosphates, the competing processes of ballistic interactions with heavy particles and ionization effects of lighter particles generally increase the "resistance" to radiation damage by enhancing the annealing processes. The ion beam irradiation results have been used to model damage accumulation in apatite, as compared with zircon, which contains $\mathrm{Pu}$ (Weber et al., 1997).

\section{Pyrochlore}

Pyrochlore, $\mathrm{A}_{2} \mathrm{~B}_{2} \mathrm{O}_{7}$, encompass a wide range of chemistries, as evident in the over 500 synthetic compositions (Chakoumakos, 1984; Chakoumakos and Ewing, 1985; Subramanian et al., 1983) and can accommodate significant amounts of actinides due to their remarkable compositional and structural flexibility. As a result, pyrochlores are important ceramics for actinide incorporation (Begg et al., 2001a; Digeos et al., 2003; Ewing, 2005; Ewing et al., 2004; Lian et al., 2003a, 2007a; Ringwood et al., 1979; Sickafus et al., 2000; Sykora et al., 2005; Wang et al., 1999c; Weber and Ewing, 2000) and are among the principal host phases considered for the disposition of $\mathrm{Pu}$ from dismantled nuclear weapons and the "minor" actinides (e.g., Np, $\mathrm{Am}, \mathrm{Cm}$ ) generated by the nuclear fuel cycle (Ewing et al., 2004). Ion beam irradiations and in situ TEM observation have been widely used to simulate $\alpha$-decay damage of crystalline waste forms under carefully controlled experimental conditions (e.g., ion mass and energy, temperature, and fluence). Ion irradiation experiments utilizing various ion species including 600 $\mathrm{keV} \mathrm{Ar}^{+}$(Wang et al., 1999c), $600 \mathrm{keV} \mathrm{Bi}^{+}$(Begg et al., 2001a), $1 \mathrm{MeV} \mathrm{Kr}^{2+}$ (Lian et al., 2003d, 2004a, 2006a,c, 2007b; Lumpkin et al., 2001, 2004; Zhang et al., 2005b), $1.5 \mathrm{MeV} \mathrm{Xe}^{+}$(Lian et al., 2002b; Wang et al., 1999b), and $400 \mathrm{keV} \mathrm{Au}^{+}$(Begg et al., 2001b; Zhang et al., 2004) were performed on the pyrochlore structure oxides $\mathrm{A}_{2} \mathrm{~B}_{2} \mathrm{O}_{7}\left(\mathrm{~A}^{3+}=\mathrm{La} \sim \mathrm{Lu}\right.$ and $\mathrm{Y} ; \mathrm{B}^{4+}=\mathrm{Ti}$, Sn, $\mathrm{Hf}$, and $\mathrm{Zr}$ ).

The systematic ion beam irradiation studies indicated that pyrochlore compositions display a wide range of responses to ion beam-induced amorphization, depend- 


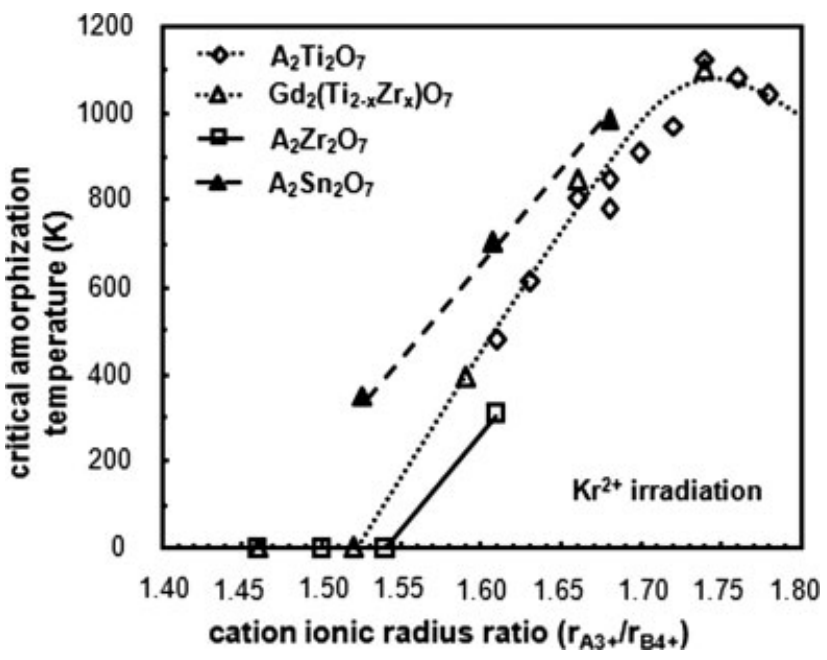

Fig. 4. The critical amorphization temperature of pyrochlores irradiated by $1 \mathrm{MeV} \mathrm{Kr}^{2+}$ as a function of the cation ionic radius ratio (Modified with permission from Ewing et al., J Appl Phys, 2004, 95, 5949-5971, American Institute Of Physics and Lian et al., J Phys Chem B, 2006a, 110, 2343-2350, American Chemical Society). The lines in this figure are a guide to the eye.

ing on the chemical composition. All of the titanate pyrochlores were readily amorphized by ion beam irradiation at a relatively low fluence. For example, $\mathrm{Gd}_{2} \mathrm{Ti}_{2} \mathrm{O}_{7}$ can be amorphized by $600 \mathrm{keV} \mathrm{Ar}^{+}$at room temperature at $\sim 0.2$ dpa (Wang et al., 1999c), a value that is consistent with the amorphization dose $(\sim 0.16 \mathrm{dpa})$ for ${ }^{244} \mathrm{Cm}-$ doped (3 wt.\%) $\mathrm{Gd}_{2} \mathrm{Ti}_{2} \mathrm{O}_{7}$ (Weber et al., 1985). With the increasing ionic radius of the A-site cation, from $\mathrm{Lu}^{3+}$ $(0.098 \mathrm{~nm})$ to $\mathrm{Gd}^{3+}(0.106 \mathrm{~nm})$, the critical amorphization temperature increases from $480 \mathrm{~K}$ (for $\mathrm{Lu}_{2} \mathrm{Ti}_{2} \mathrm{O}_{7}$ ) to $1,120 \mathrm{~K}$ (for $\mathrm{Gd}_{2} \mathrm{Ti}_{2} \mathrm{O}_{7}$ ) (Lian et al., 2003a, 2006a). Zirconate pyrochlores are generally resistant to radiationinduced amorphization, and both $\mathrm{Gd}_{2} \mathrm{Zr}_{2} \mathrm{O}_{7}$ and $\mathrm{Er}_{2} \mathrm{Zr}_{2} \mathrm{O}_{7}$ remain crystalline at doses as high as $100 \mathrm{dpa}$ at room temperature (Lian et al., 2002b; Sickafus et al., 2000; Wang et al., 1999c). A radiation-induced crystalline-to-amorphous transformation was observed in $\mathrm{La}_{2} \mathrm{Zr}_{2} \mathrm{O}_{7}$ with both $1 \mathrm{MeV} \mathrm{Kr}^{2+}$ (Lumpkin et al., 2004) and $1.5 \mathrm{MeV} \mathrm{Xe}^{+}$irradiations (Lian et al., 2002b), despite the fact that the critical amorphization temperature of $\mathrm{La}_{2} \mathrm{Zr}_{2} \mathrm{O}_{7}$ is relatively low $(\sim 300 \mathrm{~K})$. Stannate pyrochlores show a diverse response to ion beam damage, from being "highly resistant" to "very sensitive" to ion beam-induced amorphization, depending on the chemical compositions (Lian et al., 2006a). Stannate pyrochlores $\mathrm{A}_{2} \mathrm{Sn}_{2} \mathrm{O}_{7}(\mathrm{~A}=\mathrm{La}, \mathrm{Nd}$, and $\mathrm{Gd})$ are readily amorphized by ion beam damage at a relatively low dose ( $\sim 1 \mathrm{dpa})$ at room temperature. However, there is no evidence of amorphization observed in $\mathrm{A}_{2} \mathrm{Sn}_{2} \mathrm{O}_{7}(\mathrm{~A}=\mathrm{Er}, \mathrm{Y}$, and $\mathrm{Lu}$ ) with $1 \mathrm{MeV} \mathrm{Kr}^{2+}$ irradiation at a dose of $\sim 6 \mathrm{dpa}$ at $25 \mathrm{~K}$ (Lian et al., 2004a).

Figure 4 summarizes the critical amorphization temperatures of all of the pyrochlore compositions subjected to $1 \mathrm{MeV} \mathrm{Kr}^{2+}$ ion irradiation as a function of the ionic radius ratio, $r_{\mathrm{A}} / r_{\mathrm{B}}$ of the $\mathrm{A}$-site and $\mathrm{B}$-site cations (Ewing et al., 2004; Lian et al., 2006a). Generally, with a decreasing radius ratio, the pyrochlore has a lower critical amorphization temperature. In other words, as the A-site cation radius approaches that of the B-site cation radius, the pyrochlore structure becomes an ideal fluorite structure and is more "resistant" to radiation-induced amorphization (Lian et al., 2003a). Instead of becoming amorphous, the pyrochlore disorders and adopts a more stable defect fluorite structure. There is, however, a significant deviation from this trend for the stannate pyrochlores, that is, the critical amorphization temperatures of stannate pyrochlores are much higher than those of titanate and zirconate pyrochlores having similar ionic radius ratios (see Fig. 4). This deviation of stannate pyrochlores from the ionic radius ratio criteria is strongly associated with the cation electronic configuration and bondtype, the stannates being much more covalent (Lian et al., 2004a, 2006a; Panero et al., 2004). The response of pyrochlore structure to ion beam irradiation is highly dependent on compositional changes, which affect both the structural deviation from the ideal fluorite structure, as well as the ionic size and bond-type. These results have significant implications for the design of radiation tolerant materials (Ewing et al., 2004).

A key limitation to the in situ TEM observations of radiation-induced amorphization is the use of a prethinned TEM foil for the ion-beam irradiation studies. The high surface-area to irradiated-volume ratio and electron-beam radiation-enhanced annealing effects may lead to the migration and annihilation of isolated defects at the surface, resulting in an overestimation of the critical amorphization dose. Thus, we have performed ion implantations in bulk samples of the single crystal zircon (Lian et al., 2003b) and lanthanide titanate pyrochlores $\mathrm{A}_{2} \mathrm{Ti}_{2} \mathrm{O}_{7}(\mathrm{~A}=\mathrm{Sm}, \mathrm{Eu}, \mathrm{Gd}$, Dy, and $\mathrm{Er})$ (Lian et al., 2005a, 2006b). Bulk sample implantations followed by cross-sectional TEM analysis provide a direct measurement of the damage profile, and a detailed microstructural characterization along the trajectory of the implanted ions may be completed. The critical amorphization dose has been determined by comparing the experimental damage profiles with those simulated using SRIM (stopping and range of ions in matters) code. A similar microstructural evolution was observed for materials upon bulk-sample ion implantation and heavy-ion irradiation during in situ TEM observation. Critical amorphization doses were overestimated for the ion irradiation using in situ TEM observations. This may result from the defect annealing at the free surface for TEM thin foils of the samples. However, a generally consistent trend in the amorphization dose at room temperature was observed for materials with different compositions. These results suggest that the combination of in situ TEM studies of radiation effects, bulk-sample ion implantation, and cross-sectional TEM characterization provide invaluable information in the investigation of the microstructural evolution and radiation response of materials.

\section{Multiple Beam Irradiation and In Situ TEM Observation}

Defect production and migration in ceramics may be significantly influenced by the simultaneous displacive and ionizing radiations. For example, e-beam irradiation may retard the crystalline-to-amorphous phase transformation as a result of ionization-enhanced defect diffusion and migration. No amorphization has 

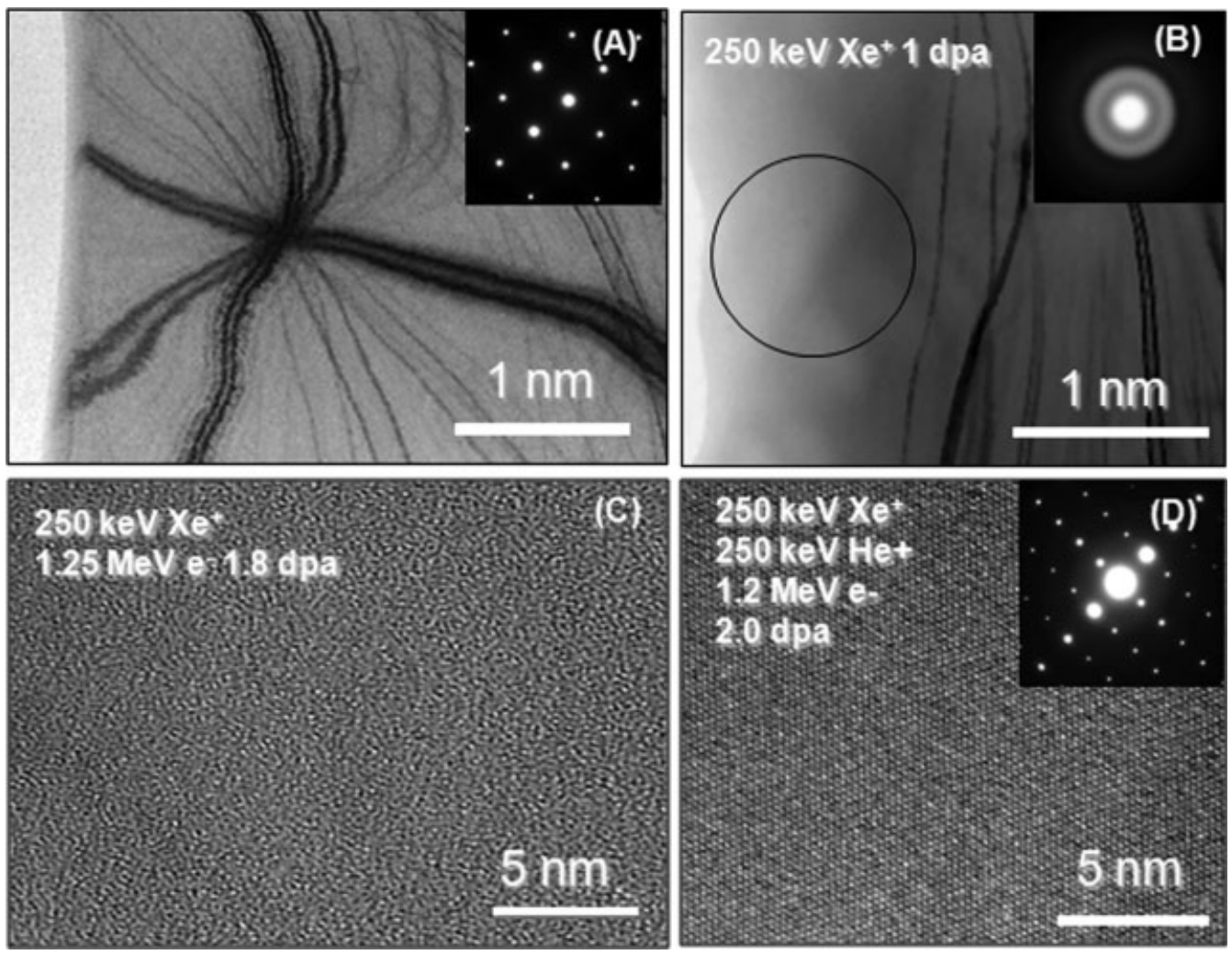

Fig. 5. Triple beam irradiation shows the effects of simultaneous displacive and ionization irradiation on materials response to radiation-induced amorphization. A: Bright-field TEM image of zircon single crystal before irradiation; B: In situ bright-field TEM image of zircon irradiated by $250 \mathrm{keV} \mathrm{Xe}{ }^{+}$at room temperature (inset is an in situ electron diffraction pattern). A completely amorphous structure can be achieved at a dose of $1 \mathrm{dpa}$ for zircon irradiated with $250 \mathrm{keV}$

been observed in $\alpha-\mathrm{Al}_{2} \mathrm{O}_{3}$ under $1.0 \mathrm{MeV} \mathrm{Kr}^{+}$-ion irradiation simultaneously with $900 \mathrm{keV}$ electrons at $26 \mathrm{~K}$; whereas, this material transformed completely to an amorphous state under a single beam irradiation of 1.0 $\mathrm{MeV} \mathrm{Kr}{ }^{+}$or $1.5 \mathrm{MeV} \mathrm{Xe}^{+}$(Devanathan et al., 1998a,b). The effect of simultaneous displacive and ionizing radiation has been discussed in terms of the ratio of electronic to nuclear stopping power (ENSP ratio, $S_{\mathrm{e}} / S_{\mathrm{n}}$ ) (Devanathan et al., 1998a). Amorphization occurred in $\mathrm{MgO}-\mathrm{Al}_{2} \mathrm{O}_{3}$ at much higher damage level for single beam ion irradiation using $12 \mathrm{MeV} \mathrm{Au}^{3+}$ (33 dpa), when compared with $400 \mathrm{keV} \mathrm{Xe}^{2+}$ (Yu et al., 1994), which can be attributed to the ionizing effects resulting from the electronic energy loss and the beam heating for $\mathrm{Au}^{3+}$ irradiations. In contrast, the swift ion irradiation with electronic stopping power greater than a critical value (typically several $\mathrm{keV} / \mathrm{nm}$ ) will induce amorphization inside the latent track at doses less than that required under irradiation mainly with displacement damage (Wiss et al., 2001; Zinkle and Skuratov, 1998).

Utilizing the state-of-the-art high voltage multibeam facilities at Hokkaido University (Sapporo, Japan), we have performed multiple beam irradiations of zircon and pyrochlore with in situ TEM observation, which allowed us to investigate the simultaneous displacive and ionizing irradiation effects. Significantly, enhanced
$\mathrm{Xe}^{+}$; C: In situ high resolution TEM image showing that complete amorphization was achieved at a dose of 1.8 dpa under double beam irradiation; and D: In situ high resolution TEM image and SAED pattern showing zircon remains crystalline subjected to triple beam irradiation at a dose of $2.0 \mathrm{dpa}$. The amorphization dose increases to 4.0 dpa under triple beam irradiation.

resistance to radiation-induced amorphization has been observed under the triple irradiation conditions when compared with the single beam-irradiation. As shown by the bright-field TEM images and selected area diffraction patterns (Figs. 5A and 5B), complete amorphization was achieved at dose of $1 \mathrm{dpa}$ in zircon single crystals with $250 \mathrm{keV} \mathrm{Xe}{ }^{+}$irradiation. With simultaneous double beam irradiations of $250 \mathrm{keV} \mathrm{Xe}$ and $1.25 \mathrm{MeV}$ e-beam the critical amorphization dose for zircon increases to $1.8 \mathrm{dpa}$. These results indicated that ionizing radiation of energetic e-beam plays an important role in determining the final microstructure of radiation-induced amorphization. In this case, e-beam ionization may enhance the defect annealing behavior and retard the amorphization process. Figure 5D shows a high-resolution TEM image and selected area diffraction pattern of zircon subjected to triple beam irradiation of $250 \mathrm{keV} \mathrm{Xe}^{+}$and $250 \mathrm{keV} \mathrm{He}^{+}, 1.25 \mathrm{MeV}$ $\mathrm{e}^{-}$. The additional $\mathrm{He}^{+}$irradiation further increases the radiation resistance to ion beam-induced amorphization, and the crystalline structure was preserved at a dose of 2 dpa upon triple beam irradiation. Complete radiation-induced amorphization of zircon was retarded until the damage level reached 4 dpa. Similar results were achieved for the irradiation of pyrochlore, $\mathrm{Gd}_{2} \mathrm{Ti}_{2} \mathrm{O}_{7}$, and complete amorphization of $\mathrm{Gd}_{2} \mathrm{Ti}_{2} \mathrm{O}_{7}$ was observed at a dose of 12 dpa under triple beam 


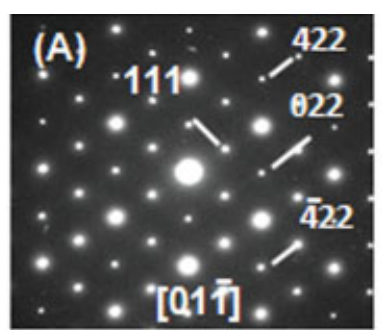

original
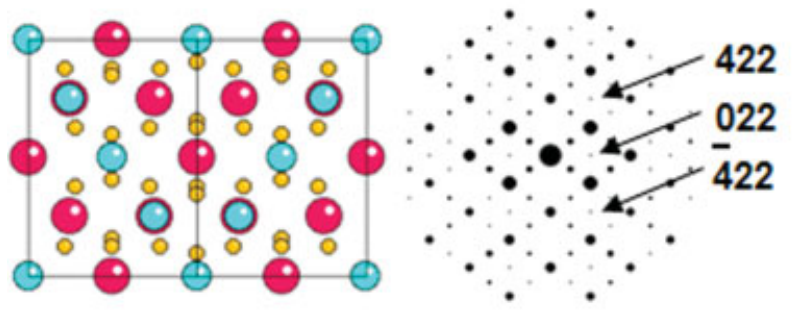

(B)

Fig. 6. A: In situ SAED diffraction patterns along the [011] zone axis of $\mathrm{Er}_{2} \mathrm{Ti}_{2} \mathrm{O}_{7}$ irradiated by $1 \mathrm{MeV} \mathrm{Kr}{ }^{2+}$ irradiation at room temperature at different doses (Lian et al., 2003c). The disappearance of specific diffraction spots $(022,422$, etc.), as marked by white arrows in the SAED pattern at $0.1 \mathrm{dpa}$, suggests that a significant anion disordering occurs upon ion irradiation; B: Structural models of a fully ordered

irradiation, which is significantly higher than the critical amorphization dose (0.2 dpa) for $\mathrm{Gd}_{2} \mathrm{Ti}_{2} \mathrm{O}_{7}$ under a single-beam irradiation (Wang et al., 1999c). These results highlight the necessity of investigating the simultaneously displacive and ionizing irradiation effects, particularly for materials subjected $\alpha$-decay events $\left(\sim 4.5 \mathrm{MeV} \mathrm{He}^{+}\right.$and $\sim 90 \mathrm{keV}$ recoil atoms), $\beta$-decay, fast neutrons, and high-energy fission fragments.

\section{RADIATION-INDUCED PHASE TRANSFORMATIONS AND ORDER-DISORDER TRANSITIONS}

Similar to crystalline-to-amorphous structural transition, in situ TEM observation can be applied to study radiation-induced phase transformations, by following selected area electron diffraction patterns under ebeam and ion beam irradiations. For example, an ebeam-induced phase transformation in $\mathrm{Pb}_{5} \mathrm{Ca}_{5}$ $\left(\mathrm{VO}_{4}\right)_{6} \mathrm{~F}_{2}$ apatite was observed under in situ TEM observation (Dong et al., 2005). Under the irradiation of the electron beam, apatite initially loses fluorine, followed by the volatilization of lead, and the formation of platelets $(2-5 \mathrm{~nm})$ of a glaserite-type structure; and finally, $\mathrm{V}^{5+}$ was reduced to $\mathrm{V}^{4+}$ with the loss of lead and calcium oxide, leading to the formation of single crystals of $\mathrm{CaVO}_{3}$ perovskite.

A pyrochlore-to-fluorite structural transformation was observed in all of the ion irradiated pyrochlores. An ion beam-induced cation and anion disordering is responsible for the pyrochlore-to-fluorite transformation (Lian et al., 2001a, 2002b; Wang et al., 1999b,c). The dynamics of the order-disorder structural trans-

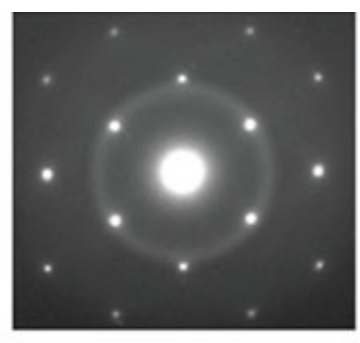

0.15

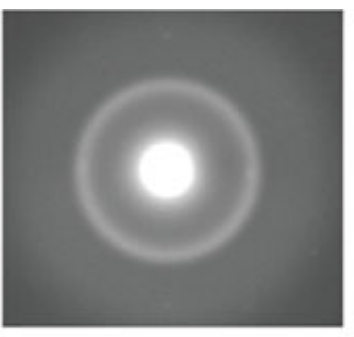

0.25 dpa
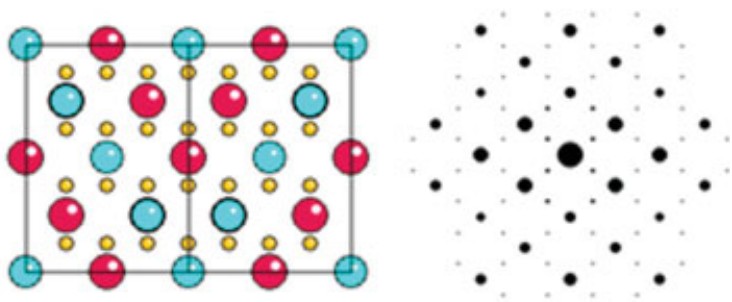

(C)

pyrochlore and the simulated diffraction patterns of $\mathrm{Er}_{2} \mathrm{Ti}_{2} \mathrm{O}_{7}$ along the [011] zone axis using Crystalkit; and C: Structural model of an anion disordered pyrochlore and simulated diffraction pattern. (Modified with permission from Lian et al., Acta Materialia, 2003c, 51, 1493-1502, Elsevier Science. [Color figure can be viewed in the online issue, which is available at www.interscience.wiley.com.]

formation in pyrochlore depends on the chemical compositions. For titanate-rich compounds, a defect fluorite was created concurrently with radiation-induced amorphous domains. With further irradiation, defect fluorite is not stable and converts to a completely amorphous state (Wang et al., 1999c). In contrast, the zirconium-rich pyrochlores do not amorphize, and ion beam-induced defect fluorite is stable to very high doses (Lian et al., 2002b, 2004b; Wang et al., 1999b). In a similar way, monoclinic zirconolite, $\mathrm{CaZrTi}_{2} \mathrm{O}_{7}$, transforms to a fluorite sublattice through cation disordering during irradiation, concurrent with amorphization process (Wang et al., 1999c).

In the pyrochlore structure, all of the atoms in the ordered pyrochlore superstructure occupy special positions in the space group $F d 3 m$, and as a result, some atoms do not make a contribution to certain diffraction maxima. For example, the extra diffraction peaks (where $h+k+l=4 n$ and individual indices $h, k$, and $l$ are not equal to a multiple of four) are contributed to only by the anion array (Hahn, 1996). Because these specific diffraction maxima are unique to the cation or anion arrays. An independent determination of the structural transitions that occur on the cation and anion sublattices during the irradiation experiments has been achieved by examining the SAED patterns using in situ TEM (Lian et al., 2003c). As shown in the SAED pattern (Fig. 6) of $\mathrm{Er}_{2} \mathrm{Ti}_{2} \mathrm{O}_{7}$ irradiated by $1 \mathrm{MeV}$ $\mathrm{Kr}^{2+}$ at a dose of $0.1 \mathrm{dpa}$, the diffraction spots with the indices $h+k+l=4 n$ (i.e., 022 and 422), originating only from the anion array, completely disappeared, in contrast to the original SAED pattern (Lian et al., 2003c). This suggests a redistribution of the anions 
within the ordered-pyrochlore superstructure. Either the anion sublattice is fully "randomized" or the intensities of diffraction maxima from the anions that are weakly ordered cannot be detected by TEM techniques due to the dynamic scattering effects. A significant amount of disordering does occur on the anion sublattices. The existence of 111 diffraction spots suggests that cations remain ordered arrangements. The decreasing intensity of these 111 diffraction maxima (Fig. 6A), when compared with those in the original pattern (Fig. $6 \mathrm{~A})$, can be attributed to the loss of contributions from anion ordering and partial cation disordering within the ordered-pyrochlore superstructure. This result suggests that cation and anion disordering occurs independently, and the anion disordering process precedes the cation disorder on ion irradiation (Lian et al., 2003c, 2004b).

To explain in situ TEM data, Lian et al. (2003c) developed a structural model of an anion-disordered pyrochlore structure, in which the cations remain completely ordered but the anions are completely disordered (Fig. 6B). The simulated diffraction patterns based on the anion-disordered pyrochlore structure using Crystalkit software have been compared with the calculated patterns of the ordered pyrochlore structure and experimental results. Extra diffraction maxima corresponding to anion-ordering reflections (i.e., 022 and 422) were observed in the simulated image based on the fully ordered pyrochlore structure. These specific diffraction maxima do not appear in the simulated image of the anion-disordered structure (Fig. 6C). The simulated SAED pattern and the experimental diffraction patterns match quite well. This result suggests that an intermediate structure, a partially disordered pyrochlore (a pyrochlore structure with significantly ordered cations but mostly disordered anions), formed upon ion beam irradiation prior to the transition from an ordered pyrochlore to the disordered defect-fluorite structure (Lian et al., 2003c, 2004b).

The formation of the anion-disordered pyrochlore structure may result from the difference between the radiation response of cation and anion sublattices due to different displacement energies. Theoretical simulations indicated that oxygen atoms may be more sensitive to ion beam damage, and the calculated mean threshold displacement energy for $\mathrm{O}_{48 \mathrm{f}}$ oxygen $(38 \mathrm{eV})$ is much smaller than that of La (153 $\mathrm{eV})$ and $\mathrm{Zr}$ (188 eV) (Chartier et al., 2003). During the displacement cascade formation at $t=0.3 \mathrm{ps}$, a significantly larger number of oxygen atoms are displaced from their equilibrium positions than are La and $\mathrm{Zr}$ atoms. Within several picoseconds ( 7.5 ps), more than $90 \%$ of the displaced anions and cations return to their initial positions or occupy an equivalent crystallographic site. Thus, this defect recovery process, due to dynamic annealing, leads to significant anion disordering but significant cation order is retained. The formation of an anion-disordered pyrochlore structure has been observed in almost all pyrochlores during ion irradiation under in situ TEM observations.

Anion-disordered pyrochlore structures were also reported recently as a result of pressure-induced compression (Zhang et al., 2005a, 2006) and mechanical milling (Fuentes et al., 2005). In particular, in situ Raman measurements of $\mathrm{Sm}_{2} \mathrm{Ti}_{2} \mathrm{O}_{7}$ at different pressures show the appearance of a new broad band around $800 \mathrm{~cm}^{-1}$ due only to anion disordering. X-ray diffraction analysis indicated the formation of a distorted pyrochlore structure upon compression, and the distortion of anion sites precedes the cation sites in titanate pyrochlores. Anions are completely disordered at a pressure of $40 \mathrm{Gpa}$; whereas the cations are still ordered up to $51 \mathrm{GPa}$ (Zhang et al., 2006).

In contrast to ion irradiation studies under in situ TEM observation (Lian et al., 2003c, 2004b) and compression studies at high pressure with in situ Raman spectroscopy measurements (Zhang et al., 2005a, 2006), Raman spectroscopy and X-ray absorption spectroscopy studies (Hess et al., 2002) of the $\mathrm{Au}^{+}$ implanted $\mathrm{Gd}_{2}\left(\mathrm{Zr}_{\mathrm{x}} \mathrm{Ti}_{1-\mathrm{x}}\right)_{2} \mathrm{O}_{7}$ system indicated that the cation disorder appears to dominate the irradiationdriven structural transition, and no significant anion disorder was observed to occur. Despite the fact that the exact mechanisms of the order-disorder transition in pyrochlores remains a subject of debate, in situ TEM observation of independent disordering kinetics of cation and anion sublattices provides another perspective for understanding the nature of the pyrochlore-to-fluorite transformation.

\section{RADIATION-INDUCED NANOSTRUCTURE FORMATION AND PHASE DECOMPOSITION}

Phase decomposition and nanostructure formation may be induced by energetic beam irradiations, and in situ TEM offers the advantage of direct observation of the phase decomposition and nanostructure formation processes as a function of radiation dose at well-controlled temperatures. Wang et al. (2000a) and Meldrum et al. (2000) summarized the examples of nanostructure formation upon ion beam and electron beam irradiations, and discussed the mechanisms responsible for nanostructure formation. Irradiation-induced nanostructures may form as a result of the overlap of the amorphous domains caused by energetic beam-induced cascade damage, leading to the formation of individual crystalline particles with a size of several $\mathrm{nm}$. These nanoparticles are embedded in amorphous matrix and may retain the original orientation of the crystal, as shown in $\mathrm{Kr}^{+}$irradiated zircon (see Fig. 2D). Similar results were observed for $\mathrm{Kr}^{+}$ion irradiated olivine (Wang et al., 1999a), garnet (Utsunomiya et al., 2002), and a niobiate titanate (Lian et al., 2001b). The nanostructures formed are apparently a result of the remnants of the original crystal. Locally, high and anisotropic strain fields, caused by irradiation and volume expansion of amorphous volume, lead to a slight rotation of the nanoparticles relative to the original crystal. Additionally, nanostructures with a random orientation may form during continued irradiation above the critical amorphization temperature. The nucleation of nanocrystals is believed to be directly from the crystalline state of the original material. The strain fields or increased dislocation density induced by energetic beam irradiations above critical amorphization temperature may also lead to randomization of orientation and refinement of grain size. Nanocrystal formation can be easily identified by in situ TEM observation by monitoring the electron diffraction pattern and noting 

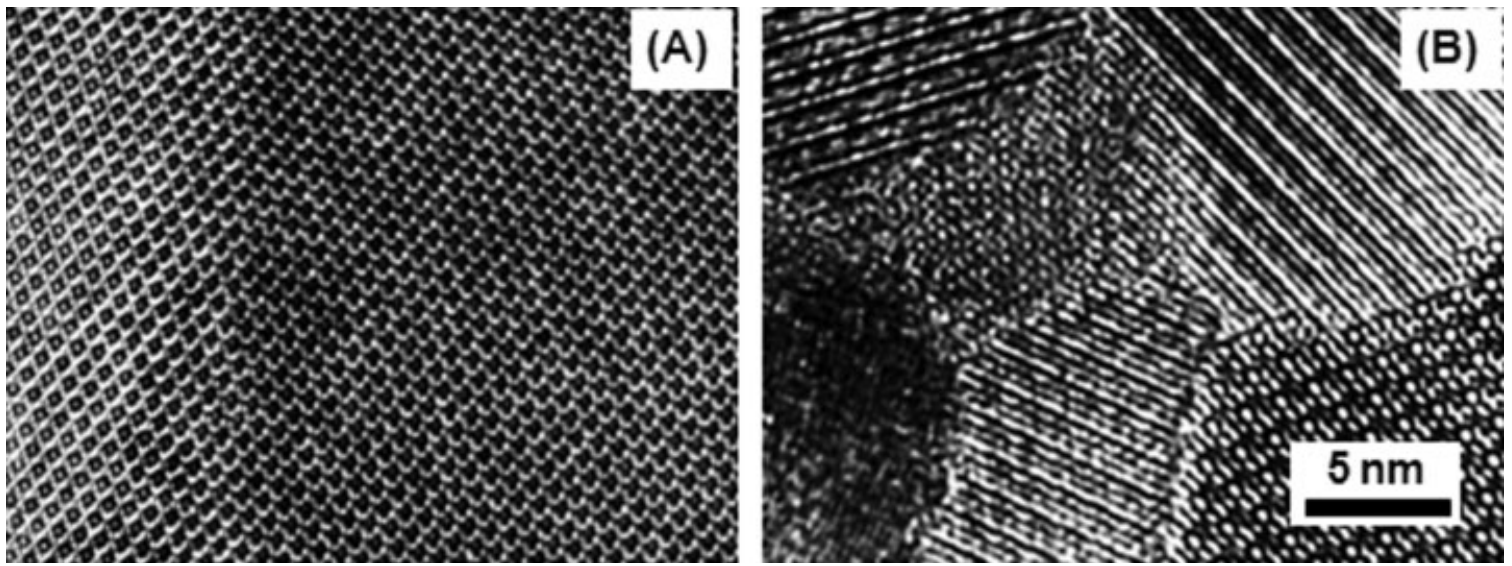

Fig. 7. Ex situ HRTEM images of a $\mathrm{Ca}_{2} \mathrm{La}_{8}\left(\mathrm{SiO}_{4}\right)_{6} \mathrm{O}_{2}$ specimen before $(\mathbf{A})$ and after $1.5 \mathrm{MeV}$ Kr irradiation to $1 \times 10^{14}$ ions $\mathrm{cm}^{2}$ at $400^{\circ} \mathrm{C}(\mathbf{B})$. The thin region of the sample has become nanocrystalline due to the irradiation (Modified with permission from Wang et al., Mater Sci Eng A, 2000a, 286, 72-80, Elsevier Sequoia).

the formation and increased intensity of the polycrystalline ring patterns.

Nanostructure formation with a random orientation can also be induced in ceramics by ion beam irradiation at temperatures near the critical amorphization temperature, below the normal crystallization temperature of corresponding amorphous materials. The nanostructure formation is a competition between amorphization and thermally activated recrystallization. In a silicateapatite, $\mathrm{Ca}_{2} \mathrm{La}_{8}\left(\mathrm{SiO}_{4}\right)_{6} \mathrm{O}_{2}$, nanocrystals readily form, as shown in ex situ HRTEM images (Fig. 7) (Wang et al., 2000a), and nanocrystals were induced by 1.5 $\mathrm{MeV} \mathrm{Kr}{ }^{+}$irradiation at a fluence of $1 \times 10^{14}$ ions $/ \mathrm{cm}^{2}$ at $673 \mathrm{~K}$, slightly below the critical amorphization temperature. The nanocrystals have the same crystal structure as the original phase as confirmed by electron diffraction. The ionization from simultaneous 300 $\mathrm{keV}$ electron beam irradiation may enhance the recrystallization process and contribute to the formation of nanocrystals with a random orientation.

Phase decomposition and chemical segregation may occur in complex ceramics (such as zircon, pyrochlore, and apatite) upon energetic beam irradiation, leading to the formation of nanocrystals with completely different chemical compositions and structures when compared with the original phase. Phase decomposition in zircon was first discovered by shock wave experiments, and tetragonal $\mathrm{ZrO}_{2}$ was identified as a decomposition product in both single-crystal and powdered zircons (Kusaba et al., 1985). Radiation damage can cause phase decomposition and lead to the formation of tetragonal $\mathrm{ZrO}_{2}$ nanocrystals, consistent with the observation in natural zircons in which $\mathrm{ZrO}_{2}$ is often found (Kusaba et al., 1985).

Utilizing in situ TEM, Meldrum et al. (1997a; Meldrum et al., 1998) reported that tetragonal or cubic zirconia nanocrystals can form directly from single crystal zircon irradiated above 1,023 K (Fig. 8A); but at $873 \mathrm{~K}$, irradiated zircon initially amorphized and finally, decomposed to $\mathrm{ZrO}_{2}$ and amorphous $\mathrm{SiO}_{2}$ (Meldrum et al., 1997a, 1998). This radiation-induced phase decomposition process can be attributed to the "liquidlike" cascades created by energetic beam irradiation.
The temperature inside a displacement cascade may be higher than temperature at which $\mathrm{ZrO}_{2}$-rich and $\mathrm{SiO}_{2}$ rich liquids can coexist. At higher irradiation temperatures (above $1,023 \mathrm{~K}$ ), $\mathrm{ZrO}_{2}$ nanocrystals nucleate and grow without directly quenching to the amorphous state (Meldrum et al., 1998). Carrez et al. (2003) further investigated the phase decomposition process by irradiating a preamorphized zircon with energetic ebeam under in situ TEM observation. First, spinodal decomposition occurred, leading to phase separation into $\mathrm{ZrO}_{2}$-rich and $\mathrm{SiO}_{2}$-rich domains. Second, small crystallites of $\mathrm{ZrO}_{2}$ nucleated and grew within the $\mathrm{ZrO}_{2}$-rich domains. An important implication of these results is that metamict zircon is not stable under ionizing radiation and tends to decompose into $\mathrm{SiO}_{2}$-rich and $\mathrm{ZrO}_{2}$-rich domains. Thus, simultaneous ionizing and displacive irradiations are required to investigate the phase stability, amorphization, and phase decomposition behavior of zircon in the event it is used as a nuclear waste form.

Phase decomposition due to energetic ion bombardments also occurred in the $(2+, 5+)$ pyrochlore $\mathrm{Cd}_{2} \mathrm{Nb}_{2} \mathrm{O}_{7}$, leading to the formation of high-density nanoparticles in the fully amorphized matrix (Jiang et al., 2005, 2006). The phase decomposition of $\mathrm{Cd}_{2} \mathrm{Nb}_{2} \mathrm{O}_{7}$ pyrochlore was observed under a wide range of irradiation conditions: $10 \mathrm{MeV} \mathrm{C}{ }^{+}, 1 \mathrm{MeV} \mathrm{He}^{+}$ (Jiang et al., 2005, 2006), $1 \mathrm{MeV} \mathrm{Kr}^{2+}$, and $30 \mathrm{keV} \mathrm{Ga}^{+}$ (Lian et al., 2006d). The nanoparticles are Cd-rich but depleted in $\mathrm{Nb}$ and $\mathrm{O}$, as indicated by energy-dispersive X-ray (EDX) measurements, and the particle size can reach $150 \mathrm{~nm}$, depending on the ion fluence and deposited energy density. The production and release of $\mathrm{O}_{2}$ molecules, the diffusion of $\mathrm{Nb}$ atoms, and the aggregation of $\mathrm{Cd}$ atoms in the amorphized region were proposed to explain the formation of $\mathrm{Cd}$-rich nanoparticles in $\mathrm{Cd}_{2} \mathrm{Nb}_{2} \mathrm{O}_{7}$. The soft metal $\mathrm{Cd}$ segregated into the phase decomposed region under ion bombardment, and then nucleated and grew in the amorphous region. The energetic ion beam irradiation may enhance the migration of $\mathrm{Cd}$, and smaller nanoparticles may coalesce, resulting in the formation of larger particles at higher irradiation fluences or at higher temperatures. In situ 


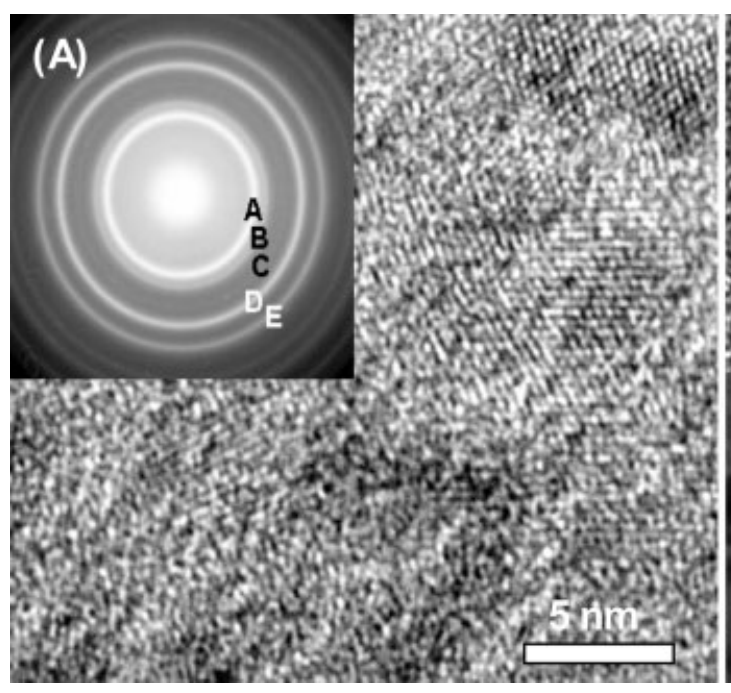

Fig. 8. A: In situ SAED pattern and ex situ HRTEM image of zircon irradiated by $800 \mathrm{keV} \mathrm{Kr}{ }^{+}$at $775^{\circ} \mathrm{C}$ to 3 dpa showing the formation of randomly oriented $\mathrm{ZrO}_{2}$ nanocrystals (highlighted) in amorphous $\mathrm{SiO}_{2}$ matrix (Modified with permission from Meldrum et al., Nucl Instrum Methods Phys Res B, 2003, 207, 28-35, North-Holland

TEM observation (Fig. 8B) shows that the nanoparticles are associated with a large number of nanopores/nanovoids. This suggests that energetic beam bombardment leads to phase decomposition within the displacement cascades, and as $\mathrm{Cd}$ segregates from the matrix and forms pure metal Cd-nanoparticles, it leaves nanopores/nanovoids enriched in $\mathrm{Nb}$ and $\mathrm{O}$. The nucleation and growth of $\mathrm{Cd}$-nanoparticles is essentially a result of phase decomposition, enrichment, and segregation of $\mathrm{Cd}$ from the matrix, incorporation into Cd-nanoparticles and coalescence of the smaller nanoparticles. The particle size is controlled by the amount of $\mathrm{Cd}$ supplied from the decomposed regions, and thus, increases with higher ion fluences and temperatures. Under $30 \mathrm{keV} \mathrm{Ga}^{+}$focused ion beam irradiation, the material only decomposed near the surface region due to the shallow penetration of the ions $(\sim 9.6 \mathrm{~nm})$ (Lian et al., 2006d). Limited amounts of free metallic Cd were available for migration; thus, the coalescence of small nanoparticles could not occur and a narrow size distribution of nanoparticles $(\sim 5 \mathrm{~nm})$ was observed in the FIB-irradiated $\mathrm{Cd}_{2} \mathrm{Nb}_{2} \mathrm{O}_{7}$ pyrochlore.

Ionization irradiation (e.g., e-beam exposure) can also cause phase decomposition. We have studied the microstructural evolution of fluorapatite, $\mathrm{Ca}_{5}\left(\mathrm{PO}_{4}\right)_{3}$ (F,OH,Cl), under $200 \mathrm{keV}$ electron beam by in situ TEM observation (Fig. 9) (Cameron et al., 1992), and with increased exposure of e-beam a radiolytic decomposition occurred, leading to the formation of a labyrinth of voids and $\mathrm{CaO}$ nanocrystals (Wang et al., $2000 \mathrm{a})$. The presence of nanocrystalline $\mathrm{CaO}$ is confirmed by both diffraction rings and Moire' fringes recorded in the electron diffraction pattern and the TEM image obtained during e-beam irradiation. The ionizing radiation first breaks the weak bonds in the apatite structure through electronic excitation

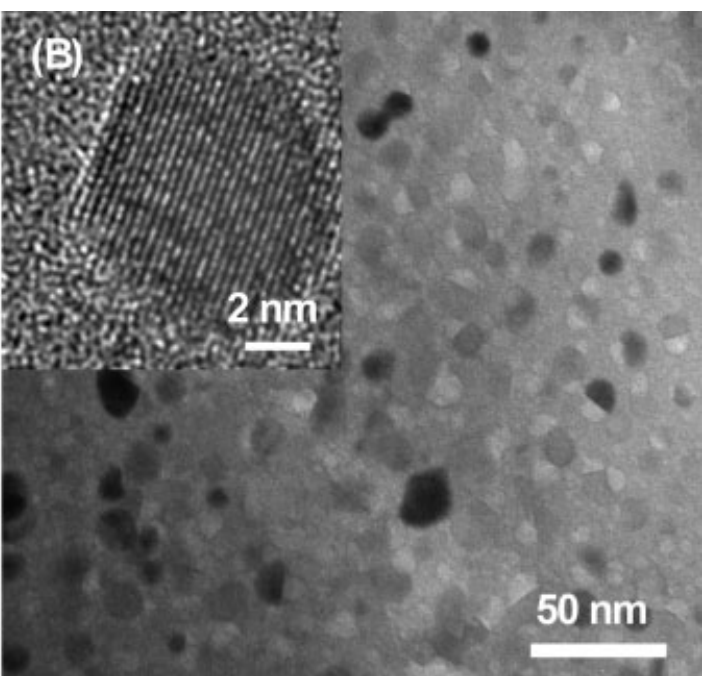

Physics Pub). The letters in the SAED pattern correspond to characteristic diffraction rings of tetragonal or cubic zirconia. B: In situ bright-field TEM and ex situ HRTEM images showing the nanoparticles formation in $\mathrm{Cd}_{2} \mathrm{Nb}_{2} \mathrm{O}_{7}$ during $1 \mathrm{MeV} \mathrm{Kr}^{2+}$ ion irradiations at $300^{\circ} \mathrm{C}$.

or a radiolysis process, causing the loss of volatile elements, such as $\mathrm{F}, \mathrm{Cl}$, and even $\mathrm{P}$, resulting in the formation of a labyrinth of cavities (Fig. 9C). Continued irradiation leads to the formation of some $\mathrm{CaO}$ crystals in the voids produced during the earlier stages of the damage process (Fig. 9D). Irradiation experiments have not revealed any significant instability of $\mathrm{CaO}$ under further electron irradiation (Cameron et al., 1992; Wang et al., 2000a). No new phosphorus-bearing or fluorine-bearing phases were identified, and no evidence of amorphization was observed by electron diffraction techniques. Additional in situ TEM observations indicated that e-beam irradiation of crystalline apatite using a high current density $\left(16 \mathrm{~A} / \mathrm{cm}^{2}\right)$ caused the precipitation of cubic $\mathrm{CaO}$ in the crystalline apatite matrix. Using a lower beam current $\left(1.6 \mathrm{~A} / \mathrm{cm}^{2}\right)$, the formation of nanometer-sized voids was observed, but $\mathrm{CaO}$ did not crystallize even after prolonged irradiation (Meldrum et al., 1997b).

\section{IONIZATION EFFECTS IN AMORPHOUS MATERIALS}

Ionization effects in zircon, synthetic $\mathrm{LaPO}_{4}$, and $\mathrm{ScPO}_{4}$ preamorphized by energetic ion beam irradiations (e.g., 1.5 $\mathrm{MeV} \mathrm{Kr}^{+}$) have been investigated upon e-beam exposure with in situ TEM over a wide range of electron beam energies $(80-200 \mathrm{kV})$ and temperatures (130-800 k). Amorphous zircon recrystallized into $\mathrm{ZrO}_{2}$ nanocrystals and amorphous $\mathrm{SiO}_{2}$ domains as a result of ionization-induced phase decomposition, and no recrystallization back to zircon occurred for any of the electron beam energies, dose rates, and temperatures (Meldrum et al., 1997a). In contrast, a randomly oriented polycrystalline assemblage of the same composition as the original material formed from the amor- 

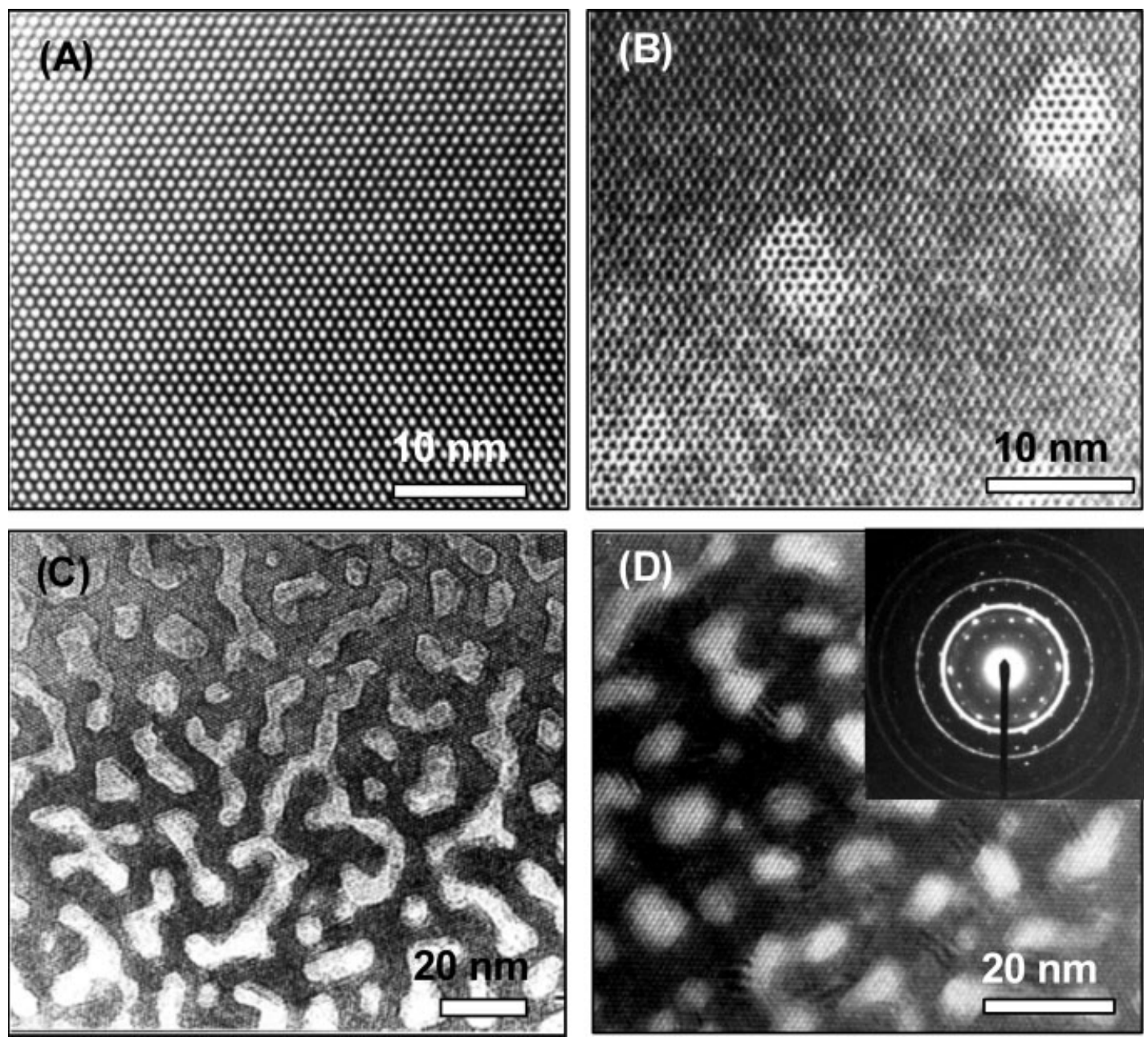

Fig. 9. The microstructure evolution of F-apatite $\left(\mathrm{Ca}_{10}\left(\mathrm{PO}_{4}\right)_{6} \mathrm{~F}_{2}\right)$ irradiated by $200 \mathrm{keV}$ electron beam under in situ TEM observation: (A) Undamaged, (B) $<1$ min after irradiation, (C) 5 min after irradiation. A labyrinth of voids has formed. (D) 10 min under irradiation.

phous $\mathrm{LaPO}_{4}$ and $\mathrm{ScPO}_{4}$ upon e-beam irradiations. Thermal annealing resulted in epitaxial recrystallization from the thick edges of the TEM samples.

Amorphous apatite recrystallized into a coarsegrained polycrystalline assemblage of apatite crystallites at $85-200 \mathrm{kV}$ at low e-beam current. Increasing the e-beam current caused the formation of fine-grained cubic $\mathrm{CaO}$, and the crystallization of apatite was not observed, even at high doses (Meldrum et al., 1997b). In each case, many e-beam-induced bubbles formed and were typically larger at the edge of the beam. Thermal annealing at $723 \mathrm{~K}$ resulted in epitaxial crystallization of the fluorapatite from the thicker, undamaged portions of the TEM foil; thus, a single crystal formed with a high defect density. These results suggest that ionizing radiation (varying with energy, dose, and dose rate) and thermally induced recrystallization have competing effects on the recrystallization behavior of amorphous materials.
$\mathrm{CaO}$ nanoparticles formed besides the voids. Inset in Figure 9D is the selected area electron diffraction pattern (Modified with permission from Wang et al., Mater Sci Eng A, 2000a, 286, 72-80, Elsevier Sequoia).
Similar to thermal annealing, ionizing radiation can also induce epitaxial recrystallization of amorphous materials. Figure 10 shows ionizing radiation-induced epitaxial annealing of an amorphous domain in $\mathrm{Ca}_{2} \mathrm{~L}-$ $\mathrm{a}_{8}\left(\mathrm{SiO}_{4}\right) \mathrm{O}_{2}$ upon e-beam irradiation (Wang and Weber, 1999). Bae et al. (2007) recently investigated the ebeam induced recystallization of irradiation-induced amorphous $\mathrm{Sr}_{2} \mathrm{Nd}_{8}\left(\mathrm{SiO}_{4}\right)_{6} \mathrm{O}_{2}$ using in situ TEM with $200 \mathrm{keV}$ electrons at room temperature. Epitaxial recrystallization was observed from both the amorphous/crystalline interface and the surface, and the recrystallization is more pronounced with increasing electron-beam flux. Using in situ TEM observation, Zhang et al. (2005b) also investigated the kinetics of ebeam-induced epitaxial recrystallization of the surface amorphous layer in $\mathrm{SrTiO}_{3}$ single crystals created by $1.0 \mathrm{MeV} \mathrm{Au}^{+}$ion implantation (Fig. 11). Under $200 \mathrm{keV}$ electron-beam irradiation, the epitaxial recrystallization rates are orders of magnitude higher than thermal 

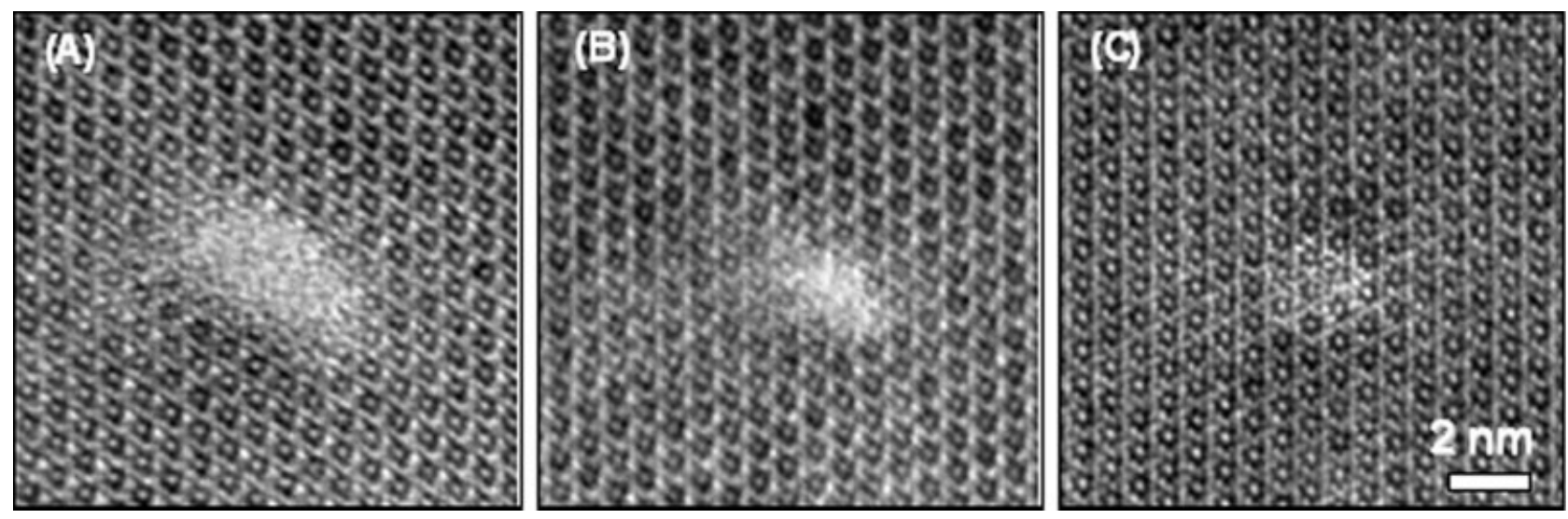

Fig. 10. Electron beam induced epitaxial annealing of an amorphous domain in $\mathrm{Ca}_{2} \mathrm{La}_{8}\left(\mathrm{SiO}_{4}\right) \mathrm{O}_{2}$ during in situ high resolution electron microscopy. The amorphous domain was created by a displacement cascade caused by a $1.5 \mathrm{MeV} \mathrm{Kr}$ ion in the crystal (Modified with permission from Wang and Weber, Philos Mag, 1999, 79, 237-253, Taylor and Francis Ltd).

rates, and an activation energy of $0.1 \pm 0.05 \mathrm{eV}$ was determined for the e-beam enhanced recrystallization, which is much lower than that of thermally-induced epitaxial growth $(0.7 \pm 0.05 \mathrm{eV}$ in air). Ionizationinduced processes are considered the primary mechanisms for the enhanced solid-phase epitaxial recrystallization under e-beam exposure. The localized electronic excitations affect local atomic bonds and may effectively lower the energy barriers to recrystallization, which may involve local atomic hopping or rotation of atomic polyhedral.

\section{APPLICATIONS OF ANALYTICAL TEM TECHNIQUES IN STUDYING RADIATION EFFECTS}

The recent development of advanced analytical TEM techniques, including high angle annual dark field imaging (HAADF), EELS, and EDS combined with conventional TEM techniques (imaging and diffraction), has provided a wide range of possibilities for probing the microstructure, microchemical composition, electronic and oxidation states of materials. Energy filtered TEM imaging, based on the characteristics of the energy loss spectrum, allows one to probe the twodimensional distribution (mapping) of elements. Simultaneous acquisition of EELS, EDS, and HAADF imaging in a dedicated STEM or a TEM/STEM makes it possible to correlate the chemical composition, electronic and oxidation state, and materials microstructure at atomic-scale resolution. However, very limited data have been reported, which utilize these advanced analytical TEM techniques in studying radiation effects in materials. Hobbs et al. (1994) have demonstrated that energy-filtered electron diffraction can be very useful for determining the radial distribution function of an amorphous material. Recently, Jiang et al. (2000, 2002) demonstrated the efficacy of combining annular dark field imaging and EELS techniques for studying phase decomposition behavior under electron irradiation in several glass systems. The combination of these analytical TEM techniques with in situ TEM observations is a powerful method for investigating radiation effects (specifically ionization-induced damage by e-beam irradiation) in materials.

Sun et al. $(2004,2005)$ have performed in situ electron energy-loss spectroscopy (EELS) and energy-filtered electron microscopy (EFTEM) studies using a JEOL-2010F STEM/TEM (in TEM mode) on a alkali borosilicate glass $\left(17.78 \% \mathrm{~B}_{2} \mathrm{O}_{3}-15.83 \% \quad \mathrm{Na}_{2} \mathrm{O}-61.39 \%\right.$ $\mathrm{SiO}_{2}-4.99 \% \quad \mathrm{Fe}_{2} \mathrm{O}_{3}$ ), a potential glass waste form for immobilization of high-level nuclear waste (HLW). Under electron beam irradiation, the glasses initially lose some mass as seen from the thinning of the glasses during the irradiation. Sodium migration to nearby regions also occurred during irradiation, and no $\mathrm{Na}$ was detected by EELS from the irradiated areas after higher doses as a result of $\mathrm{Na}$-depleted areas in the irradiated glass. With increasing electron doses, a phase separation phenomenon was observed leading to a borate phase from the silica-rich phase (see Z-contrast image in Fig. 12A). A HREM image shows the formation of small crystalline particles with an interplanar distance of $\sim 0.26 \mathrm{~nm}$, after the glass has been irradiated at a high electron dose. In situ EFTEM images (Figs. 12B-12E) (RGB map generated from elemental mapping) clearly shows the process of phase separation under irradiation, and $\mathrm{Fe}$ is associated with a boronrich phase in the Fe-containing glasses (Sun et al., 2005).

Figure 13 shows a series of in situ EELS spectra containing Si L $\mathrm{L}_{23}$-edge and B K-edge in sodium borosilicate glasses under electron irradiation (Sun et al., 2004). Si $\mathrm{L}_{23}$ core-loss spectrum (spectrum 1) was acquired at the electron dose of $3.2 \times 10^{10}$ Gy and has features characteristic of amorphous $\mathrm{SiO}_{2}$ with tetrahedrally coordinated $\mathrm{Si}$. With increasing electron doses, no obvious chemical shifts were observed from the $\mathrm{Si}_{23}$ spectra. Two sharp peaks at the energies of 108 and $115 \mathrm{eV}$ remain with little change in the relative intensities, suggesting that only a small amount of Si was reduced and most $\mathrm{Si}$ atoms maintain their tetrahedral coordination during the irradiation. The B K-edge 

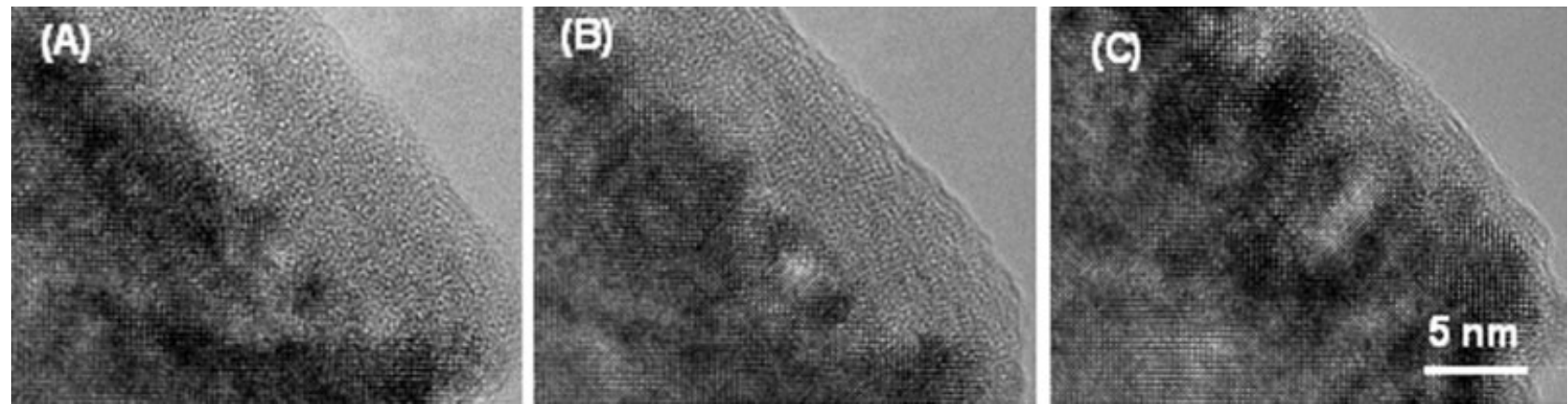

Fig. 11. In situ high resolution TEM images (cross-sectional view) of $\mathrm{SrTiO}_{3}$ preamorphized by 1.0 $\mathrm{MeV} \mathrm{Au}^{+}$under $200 \mathrm{keV}$ e-beam exposure at different time (A: original; B: $40 \mathrm{~s}$; and $\mathbf{C}: 180 \mathrm{~s}$ ) with flux of $5.0 \times 10^{20} \mathrm{~cm}^{-2} \mathrm{~s}^{-1}$ showing ionizing radiation-induced epitaxial recrystallization along the amorphous/crystalline interface.
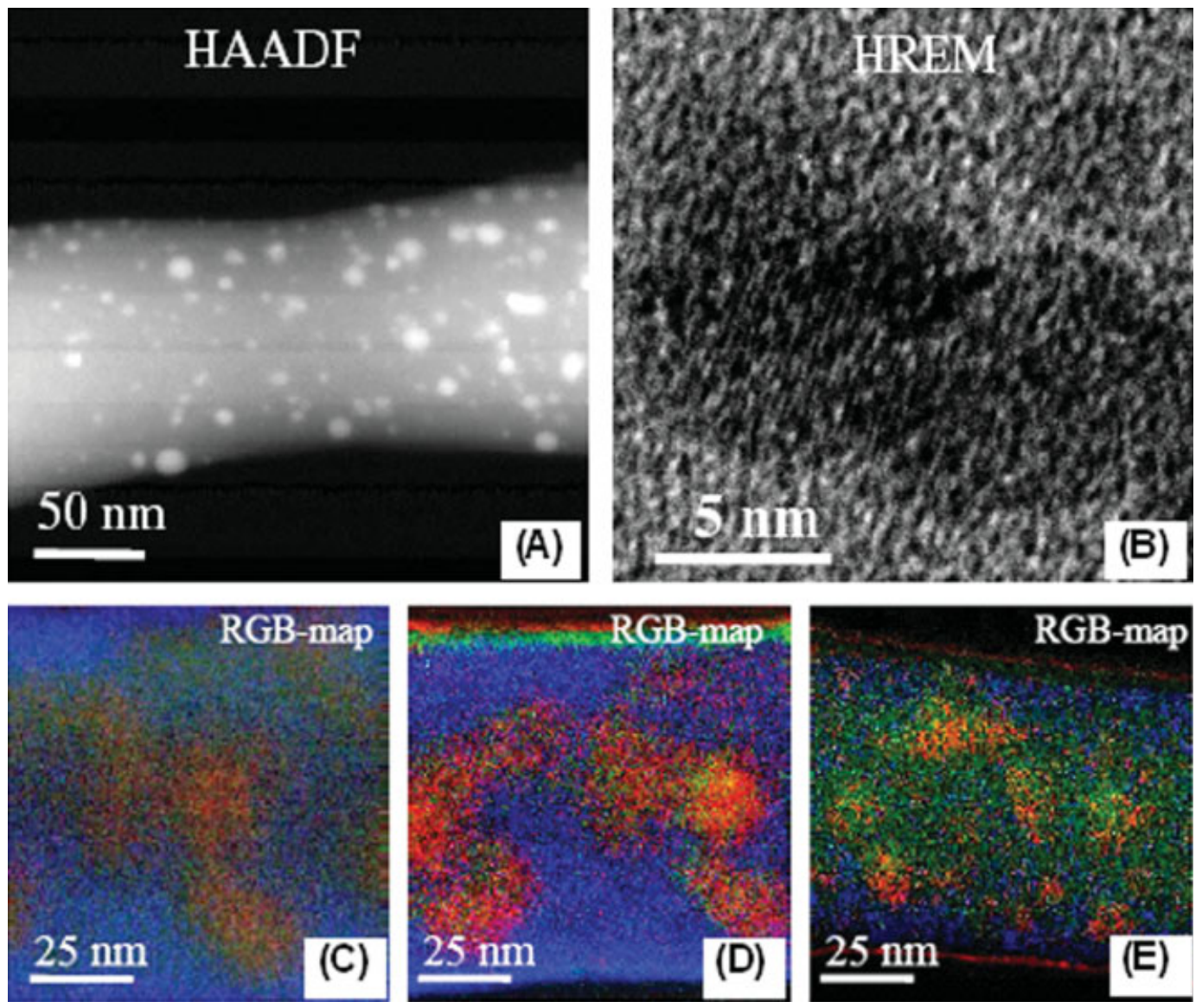

Fig. 12. HAADF image (A) and high resolution TEM image (B) showing a boron-rich phase separation from a sodium borosilicate (NBS) glass irradiated by $200 \mathrm{keV}$ e-beam at a fluences of $3.0 \times 10^{26}$ $\mathrm{e} / \mathrm{m}^{2}$. (C-E) RGB maps (R: B, G: Fe, and B: Si) generated from in situ
EFTEM images (elemental maps) of a sodium borosilicate glass irradiated at doses of about $(\mathbf{C}) 2.0 \times 10^{26}$, (D) $3.0 \times 10^{26}$, and (E) $5.0 \times$ $10^{26} \mathrm{e} / \mathrm{m}^{2}$. [Color figure can be viewed in the online issue, which is available at www.interscience.wiley.com.] spectrum acquired at a dose of $3.2 \times 10^{10} \mathrm{~Gy}$ (spectrum 1) consists of a sharp peak $\left(\pi^{*}\right)$ at about $193 \mathrm{eV}$ followed by a broad peak $\left(\sigma^{*}\right)$ at $203 \mathrm{eV}$, with the former having a slightly greater intensity than the latter peak. This suggests that B atoms are mainly in triangular coordi- nation and tetrahedral $\mathrm{B}$ is minor. With increasing irradiation dose, there was initially an increase of the intensity ratio between the $\pi^{*}$ and the $\sigma^{*}$ peak, which then decreased with further irradiation. $B$ in the sodium borosilicate glass is reduced from its original 

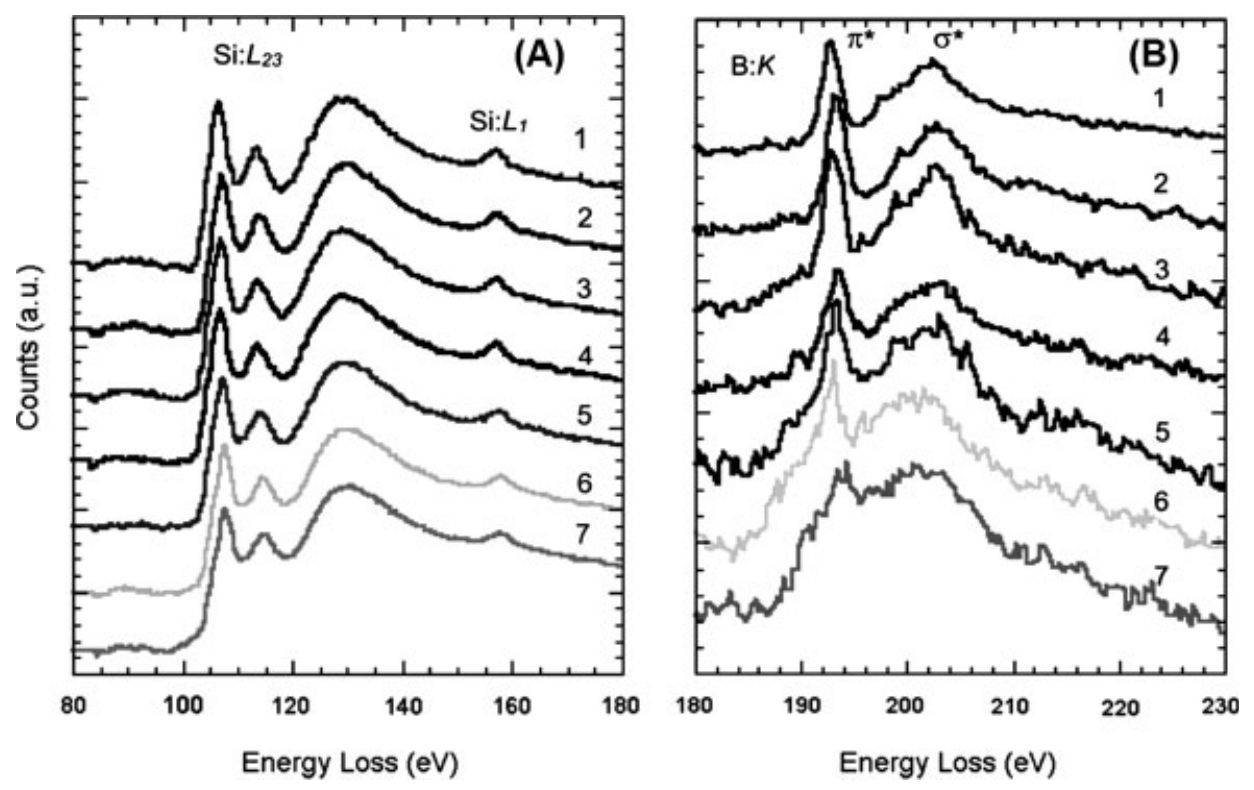

Fig. 13. In situ EELS spectrum from Si $\mathrm{L}_{23}$ edge and B K-edge from a NBS irradiated by $200 \mathrm{keV}$ ebeam at doses of (1) $3.0 \times 10^{10}$, (2) $2.5 \times 10^{11}$, (3) $4.8 \times 10^{11}$, (4) $8.2 \times 10^{11}$, (5) $1.1 \times 10^{12}$, (6) $1.4 \times 10^{12}$, and (7) $2.1 \times 10^{12}$ Gy, respectively (Modified with permission from Sun et al., Nucl Instrum Methods Phys Res B, 2004, 218, 368-374, North-Holland Physics Pub).

oxidation state during irradiation, accompanying its separation from the Si-rich phase. These results demonstrated that in situ EELS analysis is a powerful technique in investigating radiation-induced oxidation state variation in glasses, especially for light elements like $\mathrm{B}$, which are difficult for analysis by conventional techniques.

\section{CONCLUSIONS}

In this article, the applications of in situ TEM techniques in the investigation of radiation effects in complex ceramics (i.e., zircon, apatite, and pyrochlore) have been summarized with the focus on radiation-induced amorphization and phase transformations. Multiple beam irradiations with in situ TEM were performed on zircon and pyrochlore to simulate the simultaneous displacive and ionization radiation effects. Examples of the microstructural evolution, microchemical variations, phase separation, decomposition, and radiationinduced nanostructure formation were presented for zircon, pyrochlore, and apatite structure types. Ion beam irradiations of zircon, combined with studies of natural zircon that contains $U$ and Th and synthetic zircon doped with $\mathrm{Pu}$ have established the validity of ion beam irradiation combined with in situ TEM to simulate the effect of $\alpha$-decay damage in complex ceramics. Systematic ion beam irradiations under in situ TEM observations in a wide range of pyrochlore compositions provide the fundamental information required to tailor materials to specific performance requirements by controlling their chemical compositions and structures. Multiple beam irradiation experiments show that ionizing radiation will significantly enhance the resistance to ballistic damage caused by energetic heavy ion irra- diations due to radiation-enhanced annealing. Thus, it is critically important to perform simultaneous displacive and ionization radiations to completely understand materials behavior in complex radiation environments. In situ techniques are particularly useful for investigating the phase transformations as a function of radiation dose and temperature. Different mechanisms responsible for radiation-induced nanostructures were elucidated by the combined use of in situ TEM observation, ex situ diffraction and TEM imaging techniques. The complex ionization effects on crystalline and amorphous materials simulated by energetic e-beam irradiations were discussed. Ionizing radiation (varying with energy, dose, and dose rate) and thermally induced recrystallization have competing effects on the recrystallization behavior of amorphous materials. We aslo demonstrated the application of advanced analytical TEM techniques, such as Z-contrast imaging, EELS, and EFTEM in studying radiation-induced microstructure evolution, phase separation, and oxidation state variations in a glass. In situ TEM combined with ex situ techniques plays a vital role in studying radiation effects in materials to achieve a fundamental understanding of energetic beam-matter interactions, damage events, and materials behavior in extreme radiation environments.

\section{ACKNOWLEDGMENTS}

The results presented here benefit from the long term collaborations with many colleagues, particularly W. J. Weber, L. A. Boatner, A. Meldrum, and S. X. Wang. The authors thank the staff of the HVEM and IVEM-Tandem Facilities at the Argonne National Laboratory for assistance during the ion irradiation 
experiments. E-beam irradiation experiments were performed using TEM facilities at Electron Microbeam Analysis Laboratory (EMAL) at University of Michigan. The authors also thank $H$. Takahashi and $H$. Kinoshita of Center of Advanced Energy Research of Hokkaido University for their support and assistance in using the high voltage multibeam facility for in situ TEM during dual ion beam irradiation at their center. This work was supported by the Office of Basic Energy Sciences, U.S. Department of Energy under grant DEFG02-97ER45656.

\section{REFERENCES}

Allen C. 1994. In situ ion- and electron-irradiation effects studies in transmission electron microscopes. Ultramicroscopy 56:200210.

Bae IT, Zhang Y, Weber WJ, Higuchi M, Giannuzzi LA. 2007. Electron-beam induced recrystallization in amorphous apatite. Appl Phys Lett 90:021912.

Begg BD, Hess NJ, McCready DE, Thevuthasan S, Weber WJ. 2001a. Heavy-ion irradiation effects on structures and acid dissolution of pyrochlores. J Nucl Mater 288:208-216.

Begg BD, Hess NJ, McCready DE, Thevuthasan S, Weber WJ. 2001b. Heavy-ion irradiation effects in $\mathrm{Gd}_{2}\left(\mathrm{Ti}_{2-\mathrm{x}} \mathrm{Zr}_{\mathrm{x}}\right) \mathrm{O}_{7}$ pyrochlores. J Nucl Mater 289:188-193.

Berry FJ, Lumpkin GR, Oates G, Whittle KR. 2005. Iron-57 Mossbauer spectroscopy study of phases in the $\mathrm{CaZrTi}_{2-2 \times} \mathrm{Nb}_{\mathrm{x}} \mathrm{Fe}_{\mathrm{x}} \mathrm{O}_{7}$ zirconolite system. Hyperfine Interact 166:363-366.

Birtcher R, Kirk M, Furuya K, Lumpkin G, Ruault M. 2005. In situ transmission electron microscopy investigation of radiation effects. J Mater Res 20:1654-1683.

Bordes N, Wang LM, Ewing RC, Sickafus KE. 1995. Ion-beaminduced disordering and onset of amorphization in spinel by defect accumulation. J Mater Res 10:981-985.

Cameron M, Wang LM, Crowley K, Ewing RC. 1992. HRTEM observation on electron irradiation damage in F-apatite. San Francisco Press. pp. 378-379.

Carrez P, Forterre C, Braga D, Leroux H. 2003. Phase separation in metamict zircon under electron irradiation. Nucl Instrum Methods Phys Res Sect B 211:549-555.

Chakoumakos BC. 1984. Systematics of the pyrochlore structure type, ideal $\mathrm{A}_{2} \mathrm{~B}_{2} \mathrm{X}_{6} \mathrm{Y}$. J Solid State Chem 53:120-129.

Chartier A, Meis C, Crocombette JP, Corrales LR, Weber WJ. 2003. Atomistic modeling of displacement cascades in $\mathrm{La}_{2} \mathrm{Zr}_{2} \mathrm{O}_{7}$ pyrochlore. Phys Rev B 67:174102.

Devanathan R, Sickafus KE, Weber WJ, Nastasi M. 1998a. Effects of ionizing radiation in ceramics. J Nucl Mater 253:113-119.

Devanathan R, Weber WJ, Sickafus KE, Nastasi M, Wang LM, Wang SX. 1998b. Cryogenic radiation response of sapphire. Nucl Instrum Methods Phys Res B 141:366-371.

Digeos AA, Valdez JA, Sickafus KE, Atiq S, Grimes RW, Boccaccini AR. 2003. Glass matrix/pyrochlore phase composites for nuclear wastes encapsulation. J Mater Sci 38:1597-1604.

Dong Z, White T, Sun K, Wang LM, Ewing RC. 2005. Electron irradiation induced transformation of $\left(\mathrm{Pb}_{5} \mathrm{Ca}_{5}\right)\left(\mathrm{VO}_{4}\right)_{6} \mathrm{~F}_{2}$ apatite to $\mathrm{CaVO}_{3}$ perovskite. J Am Ceram Soc 88:184-190.

Eby RK, Ewing RC, Birtcher RC. 1992. The amorphization of complex silicates by ion beam irradiation. J Mater Res 7:3080-3102.

Ewing RC. 2005. Plutonium and "minor" actinides: Safe sequestration. Earth Planet Sci Lett 229:165-181.

Ewing RC, Wang LM. 1992. Amorphization of zirconolite - alphadecay event damage versus krypton ion irradiation. Nucl Instrum Methods Phys Res B 65:319-323.

Ewing RC, Meldrum A, Wang LM, Wang SX. 2000. Radiation-induced amorphization. Transform Processes Miner 39:319-361.

Ewing RC, Meldrum A, Wang LM, Weber WJ, Corrales LR. 2003. Radiation effects in zircon. Zircon 53:387-425.

Ewing RC, Weber WJ, Lian J. 2004. Nuclear waste disposal-pyrochlore $\left(\mathrm{A}_{2} \mathrm{~B}_{2} \mathrm{O}_{7}\right)$ : Nuclear waste form for the immobilization of plutonium and "minor" actinides. J Appl Phys 95:5949-5971.

Fuentes AF, Boulallya K, Maczka M, Hanuza J, Amador U. 2005. Synthesis of disordered pyrochlores, $\mathrm{A}_{2} \mathrm{Ti}_{2} \mathrm{O}_{7}(\mathrm{~A}=\mathrm{Y}, \mathrm{Gd}$ and $\mathrm{Dy})$, by mechanical milling of constituent oxides. Solid State Sci 7:343-353.

Hadley JH, Hsu FH, Vance ER, Colella M, Smith KL, Lumpkin GR, Carter ML, Begg BD. 2005. Cation vacancies in doped zirconolite $\left(\mathrm{CaZrTi}_{2} \mathrm{O}_{7}\right)$. J Mater Sci 40:6029-6032.

Hahn T, editor. 1996. International tables for crystallography, 4th ed. Kluwer. 686 p.
Hess NJ, Begg BD, Conradson SD, McCready DE, Gassman PL, Weber WJ. 2002. Spectroscopic investigations of the structural phase transition in $\mathrm{Gd}_{2}\left(\mathrm{Ti}_{1-\mathrm{y}} \mathrm{Zr}_{\mathrm{y}}\right)_{2} \mathrm{O}_{7}$ pyrochlores. $\mathrm{J}$ Phys Chem B 106:4663-4677.

Hobbs LW. 1994. Topology and geometry in the irradiation-induced amorphization of iinsulators. Nucl Instrum Methods Phys Res B 91:30-42.

Hobbs LW. 1995. The role of topology and geometry in the irradiationinduced amorphization of network structures. J Non-Cryst Solids 182:27-39.

Hobbs LW, Clinard FW, Zinkle SJ, Ewing RC. 1994. Radiation effects in ceramics. J Nucl Mater 216:291-321.

Hobbs LW, Sreeram AN, Jesurum CE, Berger BA. 1996. Structural freedom, topological disorder, and the irradiation-induced amorphization of ceramic structures. Nucl Instrum Methods Phys Res B 116:18-25.

Ishino S. 1997. A review of in situ observation of defect production with energetic heavy ions. J Nucl Mater 251:225-236.

Jesurum CE, Pulim V, Hobbs LW. 1998. Topological modeling of amorphized tetrahedral ceramic network structures. J Nucl Mater 253:87-103.

Jiang N, Qiu JR, Silcox J. 2000. Precipitation of nanometer scale Zn crystalline particles in $\mathrm{ZnO}-\mathrm{B}_{2} \mathrm{O}_{3}-\mathrm{SiO}_{2}$ glass during electron irradiation. Appl Phys Lett 77:3956-3958.

Jiang N, Qiu JR, Gaeta AL, Silcox J. 2002. Nanoscale modification of optical properties in Ge-doped $\mathrm{SiO}_{2}$ glass by electron-beam irradiation. Appl Phys Lett 80:2005-2007.

Jiang W, Weber WJ, Wang C, Young J, Boatner LA, Lian J, Wang LM, Ewing RC. 2005. Nanostructures on ion-cleaved surface of cadmium niobate pyrochlore. Adv Mater 17:1602-1606.

Jiang W, Weber WJ, Young J, Boatner LA, Lian J, Wang LM, Ewing RC 2006. Irradiation-induced nanostructures in cadmium niobate pyrochlores. Nucl Instrum Methods Phys Res B 250:188-191.

Kusaba K, Syono Y, Kikuchi M, Fukuoka K. 1985. Shock behavior of zircon: Phase transition to scheelite structure and decomposition. Earth Planet Sci Lett 72:433-439.

Lian J, Wang LM, Wang SX, Chen J, Boatner LA, Ewing RC. 2001a. Nanoscale manipulation of pyrochlore: New nanocomposite ionic conductors. Phys Rev Lett 87:145901.

Lian J, Wang SX, Wang LM, Ewing RC. 2001b. Radiation damage and nano-crystal formation in uranium-niobium titanates. J Nucl Mater 297:89.

Lian J, Wang LM, Ewing RC, Lumpkin GR. 2002a. Heavy ion irradiation effects of brannerite-types ceramics. Nucl Instrum Methods Phys Res B 191:565.

Lian J, Zu XT, Kutty KVG, Chen J, Wang LM, Ewing RC. 2002b. Ionirradiation-induced amorphization of $\mathrm{La}_{2} \mathrm{Zr}_{2} \mathrm{O}_{7}$ pyrochlore. Phys Rev B 66:054108.

Lian J, Chen J, Wang LM, Ewing RC, Farmer JM, Boatner LA, Helean KB. 2003a. Radiation-induced amorphization of rare-earth titanate pyrochlores. Phys Rev B 68:134107.

Lian J, Rios S, Boatner LA, Wang LM, Ewing RC. 2003b. Microstructure evolution and nanocrystal formation of $\mathrm{Pb}$ implanted zircon single crystals. J Appl Phys 94:5695-5703.

Lian J, Wang LM, Chen J, Sun K, Ewing RC, Farmer JM, Boatner LA. 2003c. The order-disorder transition in ion-irradiated pyrochlore. Acta Mater 51:1493-1502.

Lian J, Wang LM, Chen J, Sun K, Ewing RC, Farmer JM, Boatner LA. 2003d. Order-disorder transition in ion irradiated pyrochlores. Acta Mater 51:1493-1502.

Lian J, Ewing RC, Wang LM, Helean KB. 2004a. Ion-beam irradiation of $\mathrm{Gd}_{2} \mathrm{Sn}_{2} \mathrm{O}_{7}$ and $\mathrm{Gd}_{2} \mathrm{Hf}_{2} \mathrm{O}_{7}$ pyrochlore: Bond-type effect. J Mater Res 19:1575-1580.

Lian J, Wang LM, Haire RG, Helean KB, Ewing RC. 2004b. Ion beam irradiation in $\mathrm{La}_{2} \mathrm{Zr}_{2} \mathrm{O}_{7}-\mathrm{Ce}_{2} \mathrm{Zr}_{2} \mathrm{O}_{7}$ pyrochlore. Nucl Instrum Methods Phys Res B 218:236-243.

Lian J, Wang LM, Ewing RC, Boatner LA. 2005a. Cross-sectional TEM Study of ion implanted lanthanide titanate pyrochlore single crystals. Nucl Instrum Methods Phys Res B 241:365-371.

Lian J, Wang LM, Ewing RC, Yudintsev SV, Stefanovsky SV. 2005b. Ion beam-induced amorphization and order-disorder structural transformation in murataite ceramics. J Appl Phys 97:113536.

Lian J, Wang LM, Ewing RC, Yudintsev SV, Stefanovsky SV. 2005c. Thermally induced phase decomposition and nanocrystal formation in murataite ceramics. J Mater Chem 15:709-714.

Lian J, Helean KB, Kennedy BJ, Wang LM, Navrotsky A, Ewing RC 2006a. Effect of structure and thermodynamic stability on the response of lanthanide stannate pyrochlores to ion beam irradiation. J Phys Chem B 110:2343-2350.

Lian J, Wang LM, Ewing RC, Boatner LA. 2006b. Microstructura evolution of ion implanted $\mathrm{Gd}_{2} \mathrm{Ti}_{2} \mathrm{O}_{7}$. Nucl Instrum Methods Phys Res B 242:448-451. 
Lian J, Weber WJ, Jiang W, Wang LM, Boatner LA, Ewing RC. 2006c. Radiation-induced effects in pyrochlore and nano-Scale materials engineering. Nucl Instrum Methods Phys Res B 250:128136.

Lian J, Zhou W, Wang LM, Boatner LA, Ewing RC. 2006d. Simultaneous formation of surface ripples and metallic nanodots induced by phase decomposition and focused ion beam patterning. Appl Phys Lett 88:093112.

Lian J, Yudintsev SV, Stefanovsky SV, Wang LM, Ewing RC. 2007a. Ion beam irradiation of U-, Th- and Ce-doped pyrochlores. J Alloys Compd 444:429-433.

Lian J, Zhang FX, Peters MT, Wang LM, Ewing RC. 2007b. Ion beam irradiation of lanthanum and thorium-doped yttrium titanates. J Nucl Mater 362:438-444.

Lumpkin GR. 2001. Alpha-decay damage and aqueous durability of actinide host phases in natural systems. J Nucl Mater 289:136-166.

Lumpkin GR. 2006. Ceramic waste forms for actinides. Elements $2: 365-372$.

Lumpkin GR, Smith KL, Blackford MG. 2001. Heavy ion irradiation studies of columbite, brannerite, and pyrochlore structure types. J Nucl Mater 289:177-187.

Lumpkin GR, Whittle KR, Rios S, Smith KL, Zaluzec NJ. 2004. Temperature dependence of ion irradiation damage in the pyrochlores $\mathrm{La}_{2} \mathrm{Zr}_{2} \mathrm{O}_{7}$ and $\mathrm{La}_{2} \mathrm{Hf}_{2} \mathrm{O}_{7}$. J Phys: Condens Matter 16:85578570.

Meldrum A, Boatner LA, Ewing RC. 1997a. Electron-irradiationinduced nucleation and growth in amorphous $\mathrm{LaPO}_{4} . \mathrm{ScPO}_{4}$, and zircon. J Mater Res 12:1816-1827.

Meldrum A, Wang L, Ewing RC. 1997b. Electron-irradiation-induced phase segregation in crystalline and amorphous apatites: A TEM study. Am Mineral 82:858-869.

Meldrum A, Zinkle SJ, Boatner LA, Ewing RC. 1998. A transient liquid-like phase in the displacement cascades of zircon, hafnon and thorite. Nature 395:56-58.

Meldrum A, Zinkle S, Boatner L, Ewing RC. 1999. Heavy-ion irradiation effects in the $\mathrm{ABO}_{4}$ orthosilicates: Decomposition, amorphization, and recrystallization. Phys Rev B 59:3981-3992.

Meldrum A, White CW, Keppens V, Boatner LA, Ewing RC. 2001. Irradiation-induced amorphization of $\mathrm{Cd}_{2} \mathrm{Nb}_{2} \mathrm{O}_{7}$ pyrochlore. Phys Rev B 63:104109-104111.

Meldrum A, Boatner LA, Ewing RC. 2003. Size effects in the irradiation-induced crystalline-to-amorphous transformation. Nucl Instrum Methods Phys Res B 207:28-35.

Panero WR, Stixrude L, Ewing RC. 2004. First-principles calculation of defect-formation energies in the $\mathrm{Y}-2(\mathrm{Ti}, \mathrm{Sn}, \mathrm{Zr})(2) \mathrm{O}-7$ pyrochlore. Phys Rev B 70:054110.

Pells G. 1994. Radiation-damage effects in alumina. J Am Ceram Soc 77:368-377.

Ringwood AE, Kesson SE, Ware NG, Hibberson W, Major A. 1979. Immobilization of high-level nuclear-reactor wastes in synroc. Nature 278:219-223.

Sabathier C, Chaumont J, Rouziere S, Traverse A. 2005. Characterisation of Ti and $\mathrm{Sr}$ atomic environments in $\mathrm{SrTiO}_{3}$ before and after ion beam irradiation by X-ray absorption spectroscopy. Nucl Instrum Methods Phys Res B 234:509-519.

Sickafus KE, Minervini L, Grimes RW, Valdez JA, Ishimaru M, Li F, McClellan KJ, Hartmann T. 2000. Radiation tolerance of complex oxides. Science 289:748-751.

Smith KL, Zaluzec NJ. 2005. The displacement energies of cations in perovskite $\left(\mathrm{CaTiO}_{3}\right)$. J Nucl Mater 336:261-266.

Smith KL, Zaluzec NJ, Lumpkin GR. 1997. In situ studies of ion irradiated zirconolite, pyrochlore and perovskite. J Nucl Mater 250:3652.

Soulet S, Carpena J, Chaumont J, Kaitasov O, Ruault MO, Krupa JC. 2001a. Simulation of the alpha-annealing effect in apatitic structures by He-ion irradiation: Influence of the silicate/phosphate ratio and of the $\mathrm{OH}^{-} / \mathrm{F}^{-}$substitution. Nucl Instrum Methods Phys Res B 184:383-390.

Soulet S, Chaumont J, Krupa JC, Carpena J. 2001b. Alpha irradiation effects in fluoroapatite and strontium titanate. Radiat Eff Defects Solids 155:189-194.

Subramanian MA, Aravamudan G, Rao GVS. 1983. Oxide pyrochlores-A review. Prog Solid State Chem 15:55-143.

Sun K, Wang LM, Ewing RC, Weber W. 2004. Electron irradiation induced phase separation in a sodium borosilicate glass. Nucl Instrum Methods Phys Res B 218:368-374.

Sun K, Wang L, Ewing RC, Weber W. 2005. Effects of electron irradiation in nuclear waste glasses. Philos Mag 85:597-608.

Sykora RE, Raison PE, Haire RG. 2005. Self-irradiation induced structural changes in the transplutonium pyrochlores $\mathrm{An}_{2} \mathrm{Zr}_{2} \mathrm{O}_{7}$ $(\mathrm{An}=\mathrm{Am}, \mathrm{Cf})$. J Solid State Chem 178:578-583.
Trachenko K, Pruneda M, Artacho E, Dove MT. 2004. Radiation damage effects in the perovskite $\mathrm{CaTiO}_{3}$ and resistance of materials to amorphization. Phys Rev B 70:134112.

Utsunomiya S, Wang LM, Yudintsev S, Ewing RC. 2002. Ion irradiation-induced amorphization and nano-crystal formation in garnets. J Nucl Mater 303:177-187.

Utsunomiya S, Yudintsev S, Wang LM, Ewing RC. 2003. Ion-beam and electron-beam irradiation of synthetic britholite. J Nucl Mater 322:180-188.

Utsunomiya S, Yudintsev S, Ewing RC. 2005. Radiation effects in ferrate garnet. J Nucl Mater 336:251-260.

Wang LM. 1998. Applications of advanced electron microscopy techniques to the studies of radiation effects in ceramic materials. Nucl Instrum Methods Phys Res B 141:312-325.

Wang LM, Ewing RC. 1992a. Detailed in situ study of ion beaminduced amorphization of zircon. Nucl Instrum Methods Phys Res B 65:324-329.

Wang LM, Ewing RC. 1992b. Ion beam induced amorphization of complex ceramic materials-minerals. Mater Res Soc Bull 17:3844.

Wang LM, Weber WJ. 1999. Transmission electron microscopy study of ion-beam-induced amorphization of $\mathrm{Ca}_{2} \mathrm{La}_{8}\left(\mathrm{SiO}_{4}\right)_{6} \mathrm{O}_{2}$. Philos Mag A 79:237-253

Wang LM, Eby R, Janecek J, Ewing RC. 1991. In situ TEM study of ion beam-induced amorphization of complex silicate structures. Nucl Instrum Methods Phys Res B 59:395-400.

Wang LM, Cameron M, Weber WJ, Ewing RC. 1994. In situ TEM observation of radiation induced amorphization in crystals with the apatite structure. In: Brown PW, Constantz B, editors. Ann Arbor, Michigan: CRC Press. pp. 243-249.

Wang SX, Wang LM, Ewing RC, Doremus RH. 1998a. Ion beaminduced amorphization in $\mathrm{MgO}-\mathrm{Al}_{2} \mathrm{O}_{3}-\mathrm{SiO}_{2}$. I. Experimental and theoretical basis. J Non-Cryst Solids 238:198-213.

Wang SX, Wang LM, Ewing RC, Doremus RH. 1998b. Ion beaminduced amorphization in $\mathrm{MgO}-\mathrm{Al}_{2} \mathrm{O}_{3}-\mathrm{SiO}_{2}$. II. Empirical model. J Non-Cryst Solids 238:214-224.

Wang LM, Gong WL, Wang SX, Ewing RC. 1999a. Comparison of ionbeam irradiation effects in $\mathrm{X}_{2} \mathrm{YO}_{4}$ compounds. J Am Ceram Soc 82:3321-3329

Wang SX, Begg BD, Wang LM, Ewing RC, Weber WJ, Kutty KVG. 1999b. Radiation stability of gadolinium zirconate: A waste form for plutonium disposition. J Mater Res 14:4470-4473.

Wang SX, Wang LM, Ewing RC, Was GS, Lumpkin GR. 1999c. Ion irradiation-induced phase transformation of pyrochlore and zirconolite. Nucl Instrum Methods Phys Res B 148:704-709.

Wang LM, Wang S, Ewing RC, Meldrum A, Birtcher R, Newcomer PP, Weber W, Matzke H. 2000a. Irradiation-induced nanostructures. Mater Sci Eng A 286:72-80.

Wang SX, Lumpkin GR, Wang LM, Ewing RC. 2000b. Ion irradiationinduced amorphization of six zirconolite compositions. Nucl Instrum Methods Phys Res B 166:293-298.

Wang SX, Wang LM, Ewing RC, Kutty KVG. 2000c. Ion irradiation of rare-earth- and yttrium-titanate-pyrochlores. Nucl Instrum Methods Phys Res B 169:135-140.

Wang SX, Wang LM, Ewing RC. 2001. Irradiation induced-amorphization: The effects of temperature, ion mass, cascade size and dose rate. Phys Rev B 63:024105-002413.

Weber WJ. 2000. Models and mechanisms of irradiation-induced amorphization in ceramics. Nucl Instrum Methods Phys Res B 166167:98.

Weber WJ, Ewing RC. 2000. Plutonium immobilization and radiation effects. Science 289:2051-2052.

Weber WJ, Wald JW, Matzke HJ. 1985. Self irradiation in $\mathrm{Gd}_{2} \mathrm{Ti}_{2} \mathrm{O}_{7}$. Mater Lett 3:173-180.

Weber WJ, Ewing R, Wang L. 1994. The radiation-induced crystalline-to-amorphous transition in zircon. J Mater Res 9:688698.

Weber WJ, Ewing RC, Meldrum A. 1997. The kinetics of alphadecay induced amorphization in zircon and apatite containing weapons-grade plutonium or other actinides. J Nucl Mater 250:147-155.

Weber WJ, Devanathan R, Meldrum A, Boatner L, Ewing RC, Wang L. 1999. The effect of temperature and damage energy on amorphization in zircon. In: Zinkle SJ, Lucas GE, Ewing RC, Williams JS, editors. Material Research Society Symposium Proceedings. Warrendale, PA. p. 367.

Wiss T, Matzke H, Rondinella VV, Sonoda T, Assmann W, Toulemonde M, Trautmann C. 2001. Damage produced in magnesium aluminate spinel by high energy heavy ions including fission products of fission energy: Microstructure modifications. Prog Nucl Energy $38: 281-286$ 
Yasuda K, Kinoshita C, Morisaki R. 1998. Role of irradiation spectrum in the microstructural evolution of magnesium aluminate spinel. Philos Mag A Phys Condens Mat Struct Defects Mech Properties 78:583-598.

Yu N, Sickafus KE, Nastasi M. 1994. First observation of amorphization in single-crystal $\mathrm{MgAl}_{2} \mathrm{O}_{4}$ spinel. Philos Mag Lett 70:235-240

Zhang Y, Weber WJ, Shutthanandan V, Devanathan R, Thevuthasan S, Balakrishnan G, Paul DM. 2004. Damage evolution on Sm and O sublattices in Au-implanted samarium titanate pyrochlore. J Appl Phys 95:2866-2872.
Zhang FX, Manoun B, Saxena SK, Zha CS. 2005a. Structure change of pyrochlore $\mathrm{Sm}_{2} \mathrm{Ti}_{2} \mathrm{O}_{7}$ at high pressures. Appl Phys Lett 86:181906.

Zhang Y, Lian J, Wang CM, Engelhard MH, Ewing RC, Weber WJ 2005 b. Enhanced recrystallization rates of amorphous $\mathrm{SrTiO}_{3}$ under electron-beam irradiation. Phys Rev B 72:094112.

Zhang FX, Manoun B, Saxena SK. 2006. Pressure-induced order-disorder transitions in pyrochlore $\mathrm{RE}_{2} \mathrm{Ti}_{2} \mathrm{O}_{7}(\mathrm{RE}=\mathrm{Y}$. Gd). Mater Lett 60:2773-2776.

Zinkle SJ, Skuratov VA. 1998. Track formation and dislocation loop interaction in spinel irradiated with swift heavy ions. Nucl Instrum Methods Phys Res B 141:737-746. 